\title{
Evaluation and refinement of closely spaced buildings' performance under near-fault ground motions
}

\author{
Mohammed Ismail ${ }^{a 1}$ and Joan-Ramon Casas ${ }^{\mathrm{b} *}$
}

${ }^{a}$ Structural Engineering Department, Zagazig University, 44519 Zagazig, Egypt; ${ }^{b}$ Department of Construction Engineering, Universitat Politècnica de Catalunya - BarcelonaTECH, Barcelona, Spain

(Received 17 April 2014; final version received 10 October 2014; accepted 13 November 2014)

This paper investigates the seismic behaviour of closely spaced fixed-base and isolated building structures in near-fault (NF) zones. Seismic pounding of fixed-base structures is considered at different heights, being from one or both opposite sides and at different seismic gap width. The response evaluation results of fixed-base buildings drive towards providing limited, but adequate, seismic gaps to perform seismic isolation. This aims at reducing structural responses with no seismic pounding under limited gaps, minimising the possible damage repair and diminishing the needed maintenance works due to strong NF earthquakes. To achieve that untraditionally, the paper presents a recently proposed seismic isolation system, named roll-incage (RNC) isolator, as a non-traditional solution to avoid direct seismic pounding of isolated buildings with their surrounding adjacent structures. It was found that the RNC isolator's buffer mechanism is able to draw down any possible pounding of the isolated superstructure to be within the isolator solid limits. This entirely prevents direct structure-tostructure pounding but on the account of amplifying its acceleration and drift responses. However, such amplified responses might lead to only minor or moderate structural damage under sever NF earthquakes with $1.20 \mathrm{~g}$ peak ground acceleration. Nevertheless, such damage could be avoided entirely using stiffer RNC isolators to achieve reduction of seismic response up to $69.0 \%$ under the same severe loading conditions and limited seismic gaps with no seismic pounding. Consequently, the RNC isolator could be an efficient solution for aseismic design in NF zones considering limited seismic gaps.

Keywords: pounding; adjacent structures; RNC isolator; buffer; near-fault; finite element; simulation

\section{Introduction}

Adjacent buildings with insufficient separation, having different dynamic characteristics, may vibrate out of phase during earthquakes causing pounding between them. The pounding of structures may lead to severe damage and even result in complete collapse. Seismic pounding damage was found to be significant between adjacent buildings during the 1985 Mexico, 1994 Northridge, 1995 Kobe, 1999 Kocaeli and 2008 Sichuan earthquakes. The concentrated local damage and increased floor accelerations in buildings are some of the major consequences of seismic pounding.

Seismic isolation technique aims at reducing the seismic damage and floor accelerations through the insertion of a flexible layer between foundation and superstructure. This achieves a fundamental time period of the system higher than the predominant energy containing time periods of earthquake ground motions. However, seismically isolated buildings are expected and allowed to experience large displacements relative to the ground during strong earthquake excitations, especially when the latter contain long period impulses (Jangid \& Kelly, 2001; Makris \& Chang, 2000). In order to accommodate such large displacements, a sufficiently wide clearance gap must be provided around the building. Such gaps, in most cases, cannot be unlimited due to practical constraints. Therefore, a reasonable concern is the possibility of pounding of a seismically isolated building against either the surrounding retaining walls or adjacent buildings during a severe earthquake.

Pounding of seismically isolated structures, using various types of seismic isolation systems, was studied numerically and parametrically in Matsagar and Jangid (2003). They concluded that pounding affects the response of a seismically isolated building more when the latter has a flexible superstructure, an increased number of stories or relatively stiff adjacent structures, which are the same conclusions of Anagnostopoulos (1988). Through parametric analyses, the effects of pounding of a seismically isolated building on the effectiveness of seismic isolation were studied in Komodromos (2008) and Polycarpou and Komodromos (2010). In those research works, the behaviour of a seismic isolation system was assumed to be linear elastic, while no other adjacent buildings were considered in the simulations. Agarwal, Niedzwecki, and va de Lindt (2007) examined the case of pounding 
between two-story buildings that were taken to be either fixed-supported or seismically isolated using a sliding isolation system with varying friction was considered. Recently, the effects of seismic pounding on the structural performance of a base-isolated reinforced concrete building have been investigated by Pant and Wijeyewickrema (2012). It was found that the performance of a baseisolated building is substantially influenced by pounding. Moreover, the degree of flexural damage due to pounding first increases with decreasing separation between structures and then decreases with further reduction in the separation.

This study aims at proposing a non-traditional solution for pounding mitigation of seismically isolated buildings with adjacent structures through the use of a recently proposed multi-feature seismic isolation device called rollin-cage (RNC) isolator. The proposed solution aims at optimising the possible damage repairs and minimising the needed maintenance works after earthquakes. The study

130 investigates how to achieve efficient seismic isolation, using the rolling-based RNC isolator, while avoiding direct structure-to-structure pounding by means of the inherent buffer mechanism of the RNC isolator, which draws any possible pounding of the superstructure down into the solid metallic body of the isolation device itself. Then, the study investigates how to alleviate any possible unwanted effects that may arise due to the inner developed pounding within the RNC isolator bounds. The potential benefit of this study will be twofold. First, the structure is seismically isolated, which means simultaneous reduction of inter-story drift, floor accelerations and base shear. Second, the needed repair works and retrofitting due to direct structure-to-structure pounding is avoided or at least minimised under severe near-fault (NF) earthquakes.

All studies are carried out herein using nonlinear timehistory analysis available in the finite-element-based code SAP2000 (Computers and Structures, Inc., 2012). Therefore, a multi-feature SAP2000 model, which was initially developed in Ismail (2013) for the RNC isolator, is improved in this paper to account for buffer damping. Then, the improved SAP2000 model of the RNC isolator is used herein to simulate the RNC isolators to consider almost all of its features, characteristics and nonlinearities. Such SAP2000 model of the RNC isolator is based on previous numerical (Ismail, Casas, \& Rodellar, 2013; Ismail, Rodellar, \& Ikhouane, 2009a, 2009b; Ismail, Rodellar, \& Ikhouane, 2010; Ismail, Rodellar, \& Ikhouane, 2012; Ismail, Rodellar, \& Pozo, 2014) and experimental (Ismail \& Rodellar, 2014a, 2014c) characterisation of the device, in addition to its full mathematical modelling published in (Ismail et al., 2013). However, none of the above publications by the authors have considered seismic pounding of RNC-isolated buildings with surrounding closely spaced structures under severe
This paper aims at providing efficient anti-seismic protection of multistory buildings (with no seismic pounding of the RNC-isolated superstructures with adjacent structures) using the RNC isolator under limited or insufficient seismic gaps and strong NF earthquakes, which are rich in displacement and velocity pulses. The problem of adjacent structures' pounding is addressed first, in this work, considering fixed-base structures. The results of this stage are used as a reference for comparison with the next stage, where the proposed approach is presented. In both stages, all adjacent structures are assumed to be fixed-base and rigid non-deformable bodies to focus mainly on the effects of the proposed approach on the the structure under consideration. In addition, to represent a virtual vertical surrounding limit that must not be exceeded by the RNC-isolated structure under consideration. The impact of certain parameters, such as the structural and isolator characteristics under severe seismic excitations, is investigated.

\section{The RNC isolator}

The existing isolation systems are based on well -known and accepted physical principles, but they are still having some functional drawbacks. Therefore, the RNC isolator has been recently proposed (Ismail, 2009; Ismail, Rodellar, \& Ikhouane, 2008; Ismail et al., 2010) as an attempt of enhancement, see Figure 1. It is a rolling-based isolation system to achieve the maximum possible structure-ground decoupling and, therefore, to minimise the seismic force transfer to the isolated structure. It is designed to achieve a balance in controlling isolator displacement demands and structural accelerations. It provides in a single unit all the necessary functions of vertical rigid support, horizontal flexibility with enhanced stability, hysteretic energy dissipation and resistance to minor vibration loads.

Although the rolling core is quasi-ellipsoidal, the RNC isolator generates no vertical fluctuation of isolated structure during motion due to the inner curvatures of the upper and lower bearing plates. Moreover, the RNC isolator is distinguished by two unique features: (1) a selfstopping (buffer) mechanism to limit the isolator displacement under severe seismic excitations, such as NF earthquakes, to a preset value by the structural designer; and (2) a linear gravity-based self-recentring mechanism that prevents residual displacement after earthquakes. Such recentring mechanism is a result of adopting a quasiellipsoidal shape of the rolling core.

Besides the rolling-based motion mechanism, which requires less lateral forces to initiate and maintain high degree of structure-ground decoupling compared to other motion mechanisms of the elastomeric-based and frictionbased isolation systems, the RNC isolator is provided with a consistent design of the lateral stiffness mechanism to get the most benefit of that rolling-based motion 
(a)
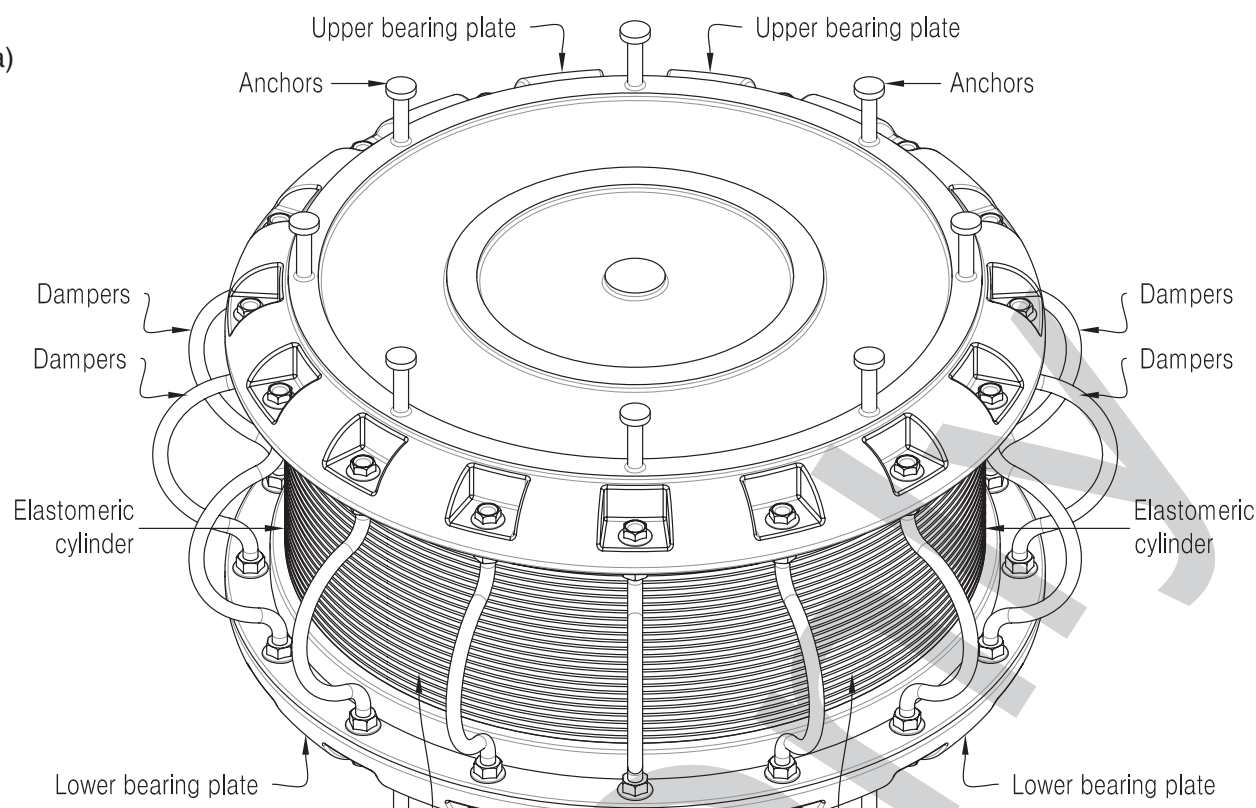

(b)

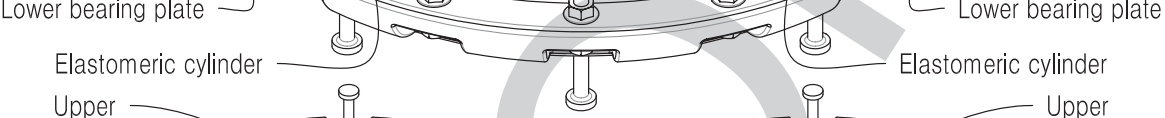

(c)
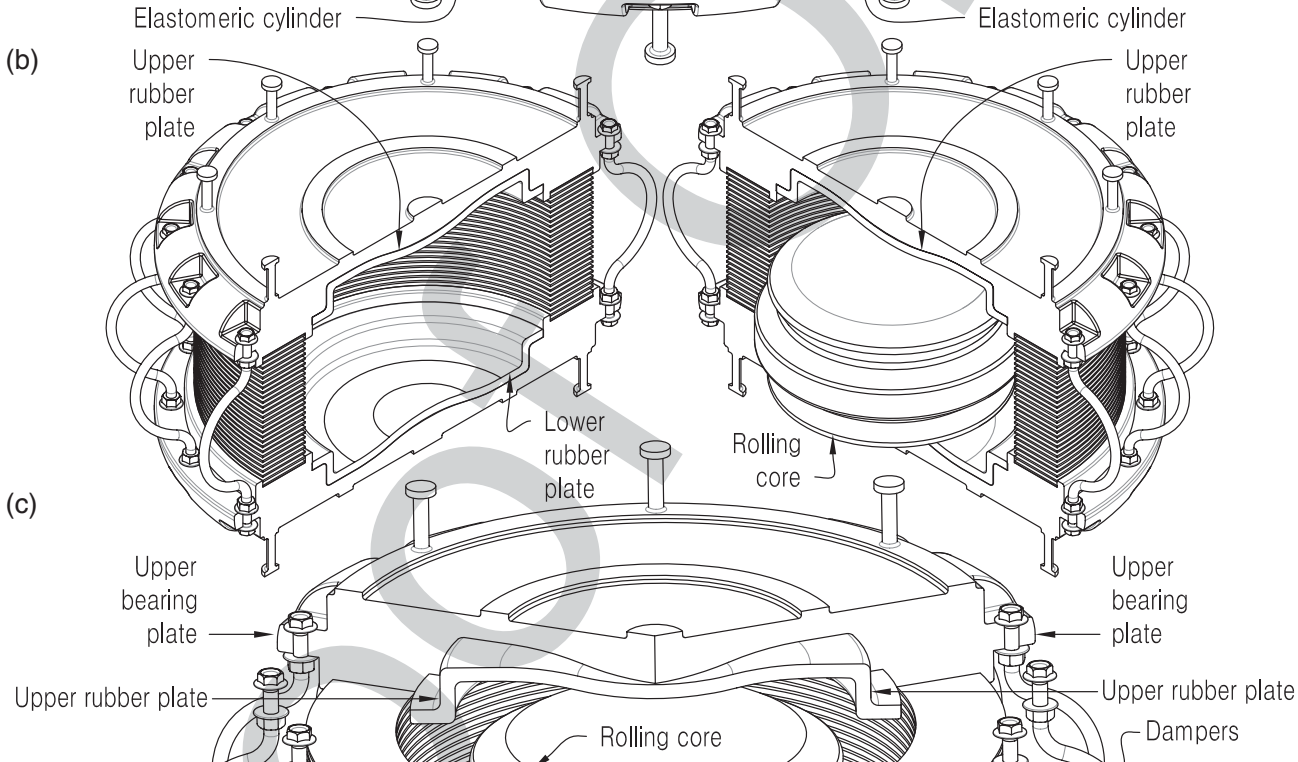

Elastomeric cylinder
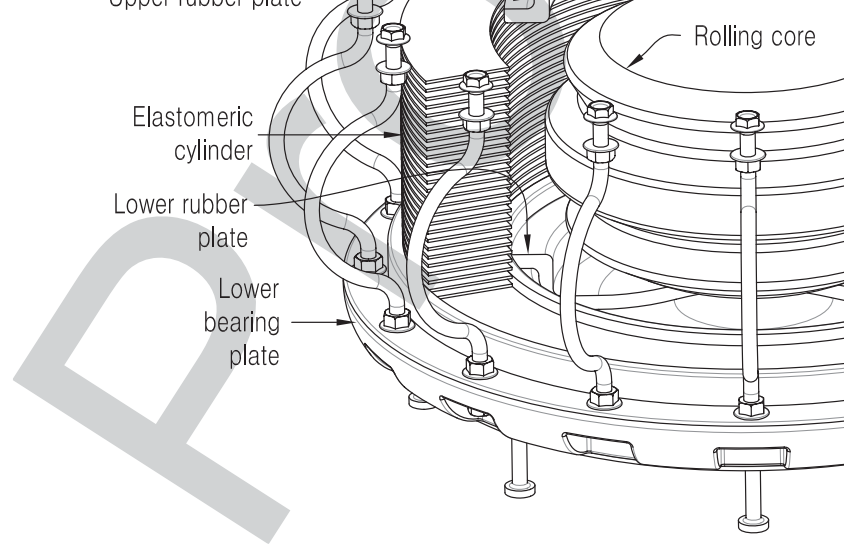

\section{e}
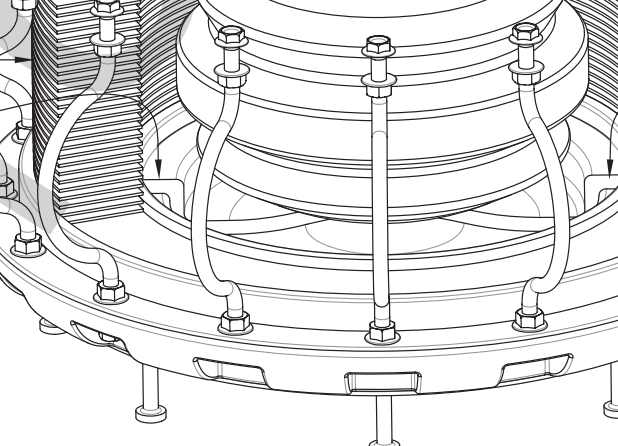
(a)

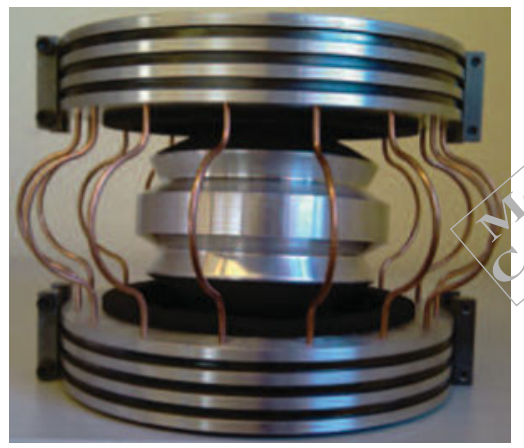

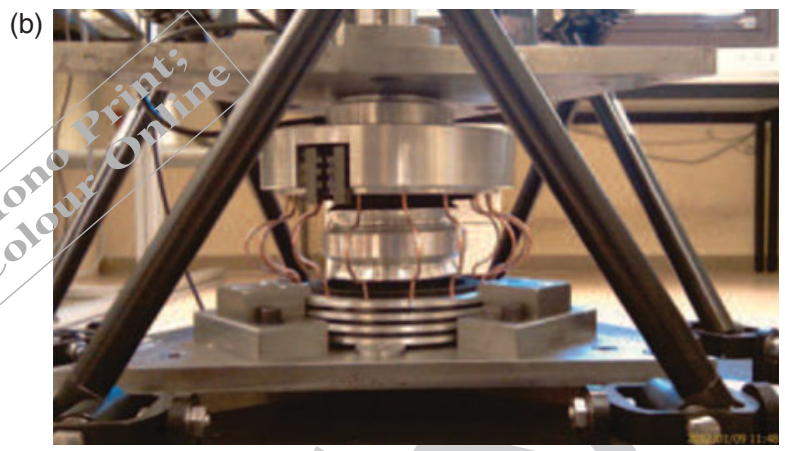

Figure 2. Experimental small-scale prototypes of the RNC isolator: (a) before experimental testing; (b) during experimental testing. structure-ground decoupling, just after the seismic forces exceed the maximum limit of minor vibration loads, contrary to the available isolation systems. To support heavy and extra heavy structures, the RNC isolator is provided with a linear hollow elastomeric cylinder, with a designed thickness, around the rolling core to represent the main vertical load carrying capacity, while the rolling core itself works as a secondary support in this case. The RNC isolator can be available in different other forms to suit the structure or object to be protected. More detailed description and thorough treatment of the RNC isolator is found in Ismail (2009).

\subsection{RNC isolator's force-displacement relationship}

Extensive series of simulation tests were carried out in Ismail et al. $(2010,2013,2014)$ to identify the mechanical characteristics of the RNC isolator using real-scale and small-scale prototypes numerically. Those tests are followed by thorough experimental verification using several sets of $1 / 10$ small-scale prototypes of the RNC isolator having different configurations, characteristics and materials. Figure 2(a) shows a constructed 1/10 reduced-scale experimental prototype of the RNC isolator having a design load of $5000.0 \mathrm{~N}$ and is made of stiff aluminium. Figure 2(b) shows the experimental prototype during dynamic testing and characterisation. More information on the experimental characterisation of the RNC isolator is found in (Ismail \& Rodellar, 2014b). It is worth mentioning that all experimental tests were directly supported and entirely funded through the director of the CoDAlab research group and are carried out using the whole facilities of the CoDAlab laboratory in Spain.

According to the deep characterisation of the RNC isolator, its measured force-displacement relationship of a corresponding real-scale modelling is of hysteretic nature with two-edge pounding peaks due to the activation of buffer mechanism under earthquakes stronger than the design earthquake, as demonstrated by Figure 3 using scaled (magnified) Imperial Valley earthquake. If the earthquake-induced isolator displacement is lower than or equal to the design displacement $x_{\text {des }}$, the RNC isolator's buffer will not be activated, leading to a typical hysteretic force-displacement relationship with no developed pounding peaks at the edges because the inner pounding is non-existent in this case, as shown in Figure 3 under non-scaled Imperial Valley earthquake.

The main three components that constitute the RNC isolator's total restoring force $F_{\mathrm{b}}$ are the linear selfrecentring component $F_{\mathrm{bR}}$, the hysteretic damping component $F_{\mathrm{bH}}$ and the linear buffer pounding component $F_{\text {bB }}$, as illustrated in Figure 4 . Figure 5 shows a schematic plot of the RNC isolator's typical complete forcedisplacement relationship with the main constituting components and parameters, while more information about full mathematical modelling of the RNC isolator is found in Ismail et al. (2013). More details about designing and building experiments are found in Ismail and Rodellar (2013) and Ismail and Rodellar (2014a, 2014c), while further information about the experimental characterisation of the RNC isolator is found in Ismail and Rodellar (2014b).

\subsection{RNC isolator's buffer}

Figure 6 shows an RNC isolator design, for light to moderate weight structures, at neutral and maximum deformed positions. Different components of the RNC isolator are configured to provide a built-in buffer mechanism. The upper and lower bearing plates have vertical right-angle edge walls, along their outer perimeters, to conform with two corresponding rightangle grooves that are cut in the rolling core's solid body. Both right-angle edge walls and grooves constitute a stiff lock mechanism after a certain design displacement, $x_{\mathrm{des}}$, that are specified by the structural designer, as shown in Figure 6(a),(c). The rigid rolling core can work as a rigid link member in compression between the upper and lower bearing plates, as shown in Figure 6(d),(f) to stop the isolator motion at this point within a small braking distance. Such braking distance depends mainly on the 


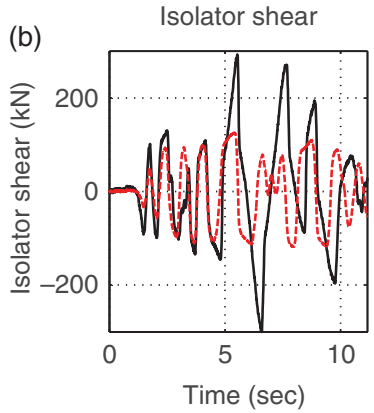

(c)
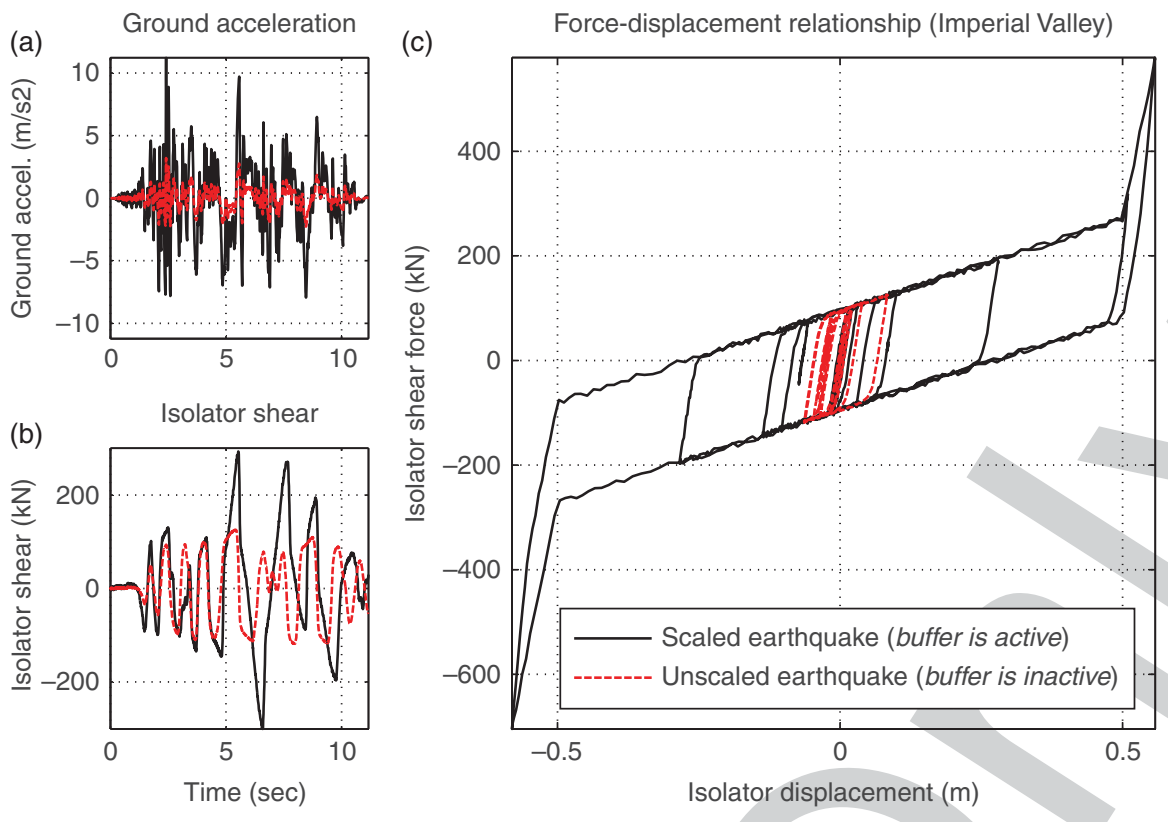

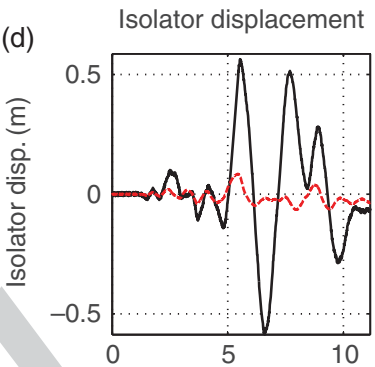

Isolator pounding

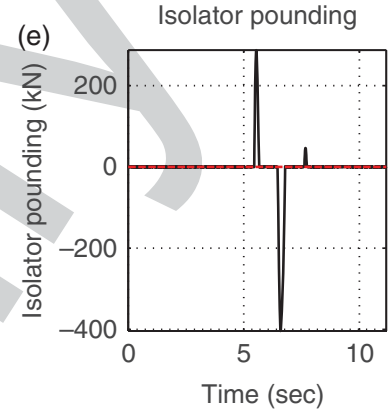

Figure 3. The force-displacement relationship of the RNC isolator under Imperial Valley earthquake, considering activation (under magnified scaled earthquake) and deactivation (under non-scaled earthquake) of the buffer mechanism: (a) input ground acceleration; (b) isolator horizontal shear force; (c) force-displacement relationship; (d) isolator horizontal shear displacement; (e) isolator inner pounding in case of active buffer mechanism (under magnified scaled earthquake).

shock severity and the lateral stiffness of the edge walls of the bearing plates. The weight of the isolated shear structure prevents the rolling core from stepping over the vertical edge walls.

The buffer mechanism aims at preventing uncontrolled isolator displacement and to maintain the isolated structure stability under earthquakes stronger than a design earthquake. In addition, it could be particularly useful in avoiding direct pounding of RNC-isolated structures with surrounding adjacent structures in the case of limited seismic gaps especially under severe ground motions, which is the main objective of this paper, because pounding (if any) will take place only within the solid metallic body of the RNC isolator.
Probably it is worth explaining the behaviour of the RNC isolator just after exceeding a certain horizontal design displacement $x_{\text {des }}$, according to Figure 5. The integrated buffer has a unique stiffness $k_{\mathrm{B}}$, which is always higher than the dampers stiffness. The $k_{\mathrm{B}}$ is activated only after exceeding the design displacement and it is represented with the steeper slope in Figure 5 in the first and the third quadrants. The activation of the buffer stiffness means deactivation of the dampers stiffness and conversely. The less steep slope is attributed to the less stiff metallic yield dampers, which are reactivated again when the buffer mechanism becomes deactivated as the $\mathrm{RNC}$ isolator reaches the end of stroke and start to reverse its direction of motion.
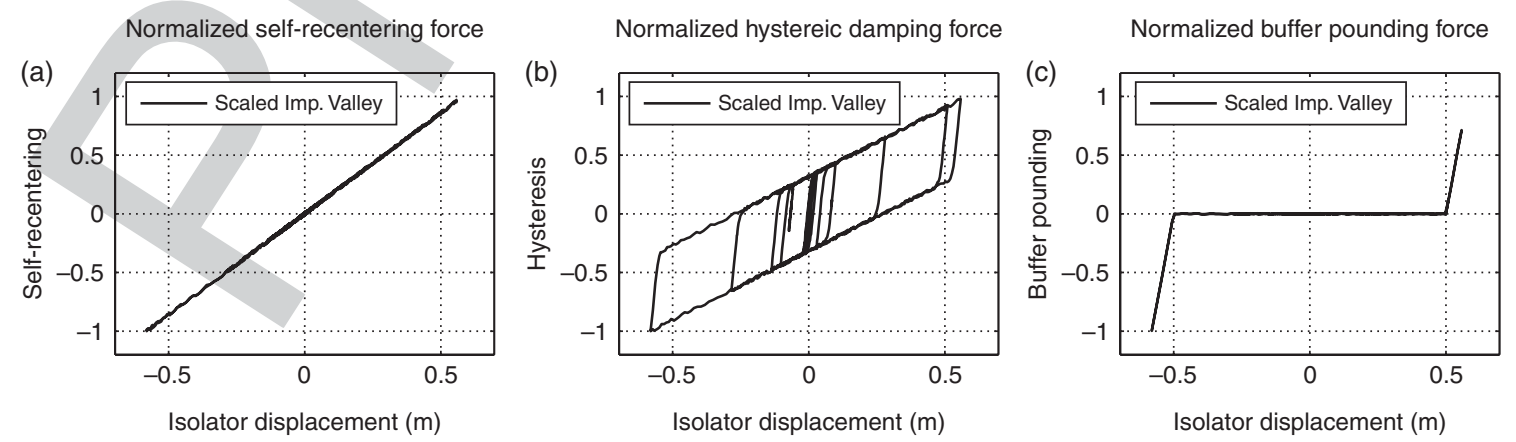

Figure 4. The normalised individual components of the force-displacement relationship of the RNC isolator under scaled Imperial 


\subsection{RNC isolator's mathematical modelling}

The main and unique features of the RNC isolator were thoroughly modelled mathematically in Ismail et al. (2013) as follows:

$$
F_{\mathrm{b}}=\left\{\begin{array}{cl}
F_{\mathrm{bH}}+F_{\mathrm{bR}} & \text { if }\left|x_{\mathrm{b}}\right|<x_{\mathrm{des}} \\
F_{\mathrm{bH}}+F_{\mathrm{bR}}+F_{\mathrm{bB}} & \text { if }\left|x_{\mathrm{b}}\right|>x_{\mathrm{des}}
\end{array}\right.
$$

where $F_{\mathrm{b}}$ is the total restoring force of the RNC isolator; $F_{\mathrm{bH}}$ is the hysteretic restoring component, which is modelled using the Bouc-Wen model (Ismail, Ikhouane, \& Rodellar, 2009); $F_{\mathrm{bR}}$ is the self-recentring component; $F_{\mathrm{bB}}$ is the buffer or self-stopping component; $x_{\mathrm{b}}$ is the base displacement and $x_{\mathrm{des}}$ is the design horizontal displacement of the RNC isolator, after which the buffer or self-stopping mechanism is activated to limit the base displacement $x_{\mathrm{b}}$. More detailed information about Equation (1) is found in Ismail et al. (2013).

\section{SAP2000 modelling of the RNC isolator}

A schematic plot of the developed SAP2000 model of the $\mathrm{RNC}$ isolator is shown in Figure 7. Such model represents a full-featured and handy model of the RNC isolator using SAP2000 away from mathematical complexities and timeconsuming computation efforts. In addition, the SAP2000 representation of the RNC isolator takes into account the following eight inherent characteristics of the isolation device:

- self-recentring;

- hysteretic damping;

- buffer or self-stopping;

- design displacement;

- vertical rigidity;

- horizontal flexibility;

- no uplift;

- pre- and post-yield stiffness.

However, the above SAP2000 modelling of the RNC isolator does not account for buffer damping. Therefore, 


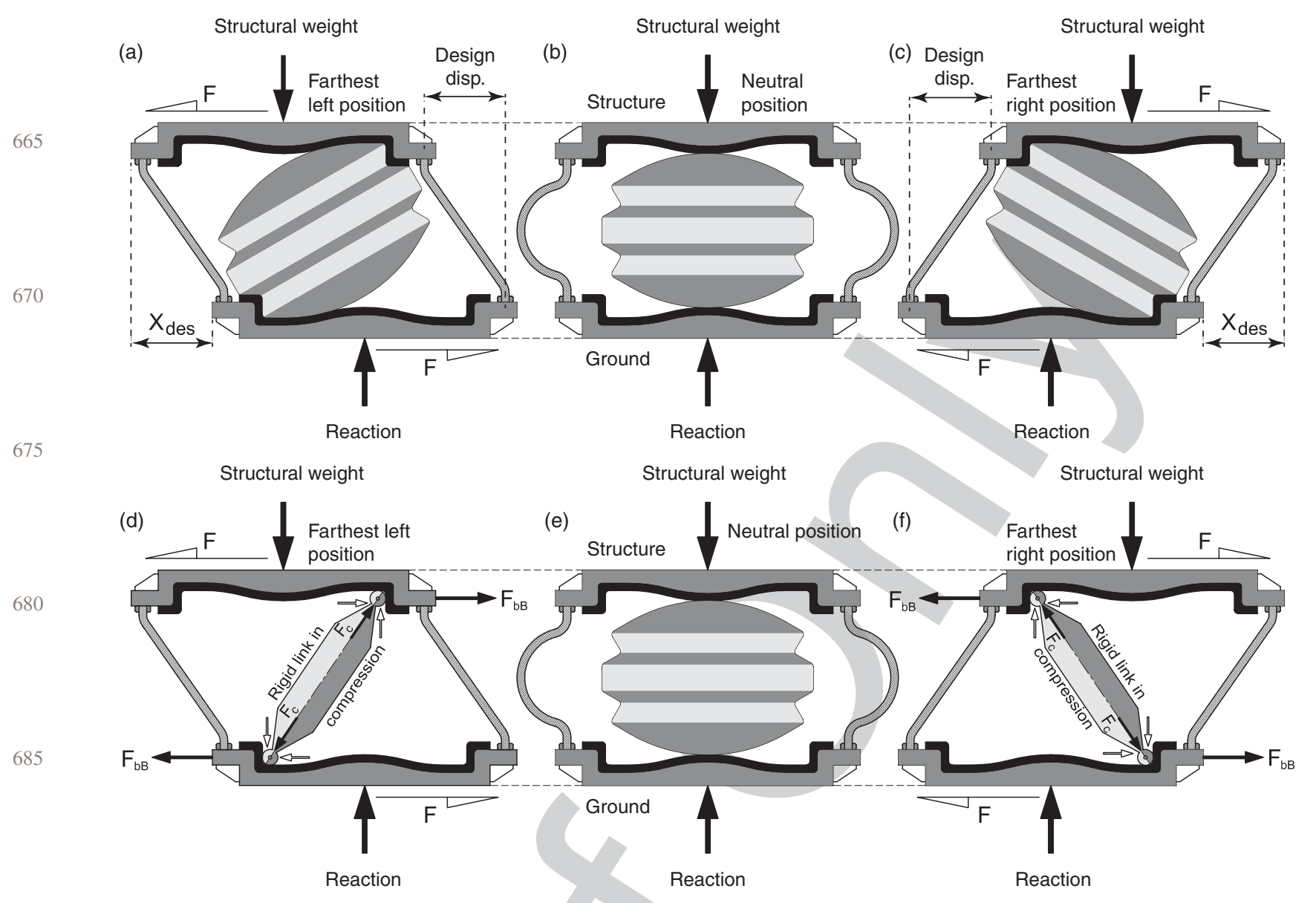

Figure 6. The integrated buffer mechanism of the RNC isolator: (a) to-the-left farthest deformed position; (b) neutral position; (c) tothe-right farthest deformed position; (d) to-the-left farthest deformed position with rigid link approximation; (e) neutral position; (f) tothe-right farthest deformed position with rigid link approximation.

such additional characteristic is appended to the model through the next section.

\subsection{Modelling of the RNC isolator's buffer mechanism's damping in SAP2000}

In Ismail et al. (2013), the RNC isolator's buffer mechanism was mathematically modelled as an elastic buffer after neglecting the buffer damping component. In the current study, a force-based impact model is used, assuming an impact spring and an impact damper exerting, in parallel, impact forces to the colliding RNC isolator's elements whenever the design distances are exceeded. Actually, it is a small variation of the linear viscoelastic impact model that had been initially proposed by Anagnostopoulos (1988), in which the tensile forces arising at the end of the restitution period are omitted and a small plastic deformation is introduced, which increases the available clearance. In particular, when a contact is detected, the RNC isolator's impact restoring force following formula:

$$
F_{\mathrm{bB}}= \begin{cases}0 & \text { if }\left|x_{\mathrm{b}}\right|<x_{\mathrm{des}}, \\ k_{\mathrm{B}}(t+\Delta t) \delta(t)+c_{\mathrm{B}} \dot{\delta}(t) & \text { if }\left|x_{\mathrm{b}}\right|>x_{\mathrm{des}}\end{cases}
$$

where $\delta(t)$ is the interpenetration depth $\left(x_{\mathrm{b}}(t)-x_{\mathrm{des}}\right), \dot{\delta}(t)$ is the relative velocity between the colliding bodies, $k_{\mathrm{B}}$ is the buffer spring's stiffness and $c_{\mathrm{B}}$ is the buffer impact damping coefficient. $c_{\mathrm{B}}$ is computed according to the following formulas, provided by Anagnostopoulos (1988), based on the conservation of energy before and after impact:

$$
\begin{gathered}
c_{\mathrm{B}}=2 \xi_{\mathrm{B}} \sqrt{k_{\mathrm{B}} \frac{m_{1} m_{2}}{m_{1}+m_{2}}}, \\
\xi_{\mathrm{B}}=-\frac{\ln (\mathrm{COR})}{\sqrt{\pi^{2}+(\ln (\mathrm{COR}))^{2}}},
\end{gathered}
$$

where $m_{1}, m_{2}$ are the masses of the two bodies, which are the superstructure above the RNC isolator and the 
Figure 7. Full modelling of the RNC isolator using SAP2000's elements.

foundation substructure below the RNC isolator, respectively; and COR is the coefficient of restitution, which is defined as the ratio of relative velocities after and before impact $(0<\mathrm{COR} \leq 1)$. The buffer damping component is represented using a gap element with zero stiffness, to represent only the design displacement, connected in series with a damper element with zero displacement too, to represent the pure buffer damping.

\subsection{Verification of the obtained SAP2000 model of the $\mathrm{RNC}$ isolator}

In this section, the validity of the obtained complete mathematical model, expressed by Equation (1), and the full SAP2000 model, illustrated in Figure 7(b), of the RNC isolator is checked. The SAP2000's model parameters are tuned, using a trial and error method, to closely match the experimentally measured force-displacement relationship of the RNC isolator shown in Figure 3(c) together with the output of the mathematical model obtained in Ismail et al. (2013). The discrepancy between the three models' outputs is quantified using the $L_{1}$ and $L_{\infty}$ norms and the corresponding relative errors $\varepsilon$ :

$$
\begin{gathered}
\|f\|_{1}=\int_{0}^{T_{\mathrm{e}}}|f(t)| \mathrm{d} t, \\
\|f\|_{\infty}=\max _{t \in\left[0, T_{\mathrm{e}}\right]}|f(t)|, \\
\varepsilon_{1, \infty}=\frac{\left\|F_{\mathrm{m}}-F_{\mathrm{b}}\right\|_{1, \infty}}{\left\|F_{\mathrm{m}}\right\|_{1, \infty}},
\end{gathered}
$$

The relative error $\varepsilon_{1}$ quantifies the ratio of the bounded area between the output curves to the area of the measured force along the excitation duration $T_{\mathrm{e}}$, while $\varepsilon_{\infty}$ measures the relative deviation of the peak force.

Table 1 lists the relative errors, $\varepsilon_{1}$ and $\varepsilon_{\infty}$, between the total restoring forces of the RNC isolator under El-Centro, Kobe and Northridge earthquakes considering three outputs: the measured, the mathematical and the SAP2000 total restoring forces. A graphical comparison between the RNC isolator's force-displacement relationship due to reduced-amplitude Northridge earthquake is

Table 1. Relative errors between the total measured, mathematically predicted and SAP2000 modelled restoring forces of the RNC isolator under El-Centro, Kobe and Northridge earthquakes.

\begin{tabular}{|c|c|c|c|c|c|}
\hline \multicolumn{2}{|c|}{ El-Centro } & \multicolumn{2}{|c|}{ Kobe } & \multicolumn{2}{|c|}{ Northridge } \\
\hline$\varepsilon_{1}(\%)$ & $\varepsilon_{\infty}(\%)$ & $\varepsilon_{1}(\%)$ & $\varepsilon_{\infty}(\%)$ & $\varepsilon_{1}(\%)$ & $\varepsilon_{\infty}(\%)$ \\
\hline 0.21 & 1.38 & 0.59 & 0.60 & 0.23 & 1.31 \\
\hline 2.74 & 0.52 & 2.19 & 1.47 & 2.32 & 1.71 \\
\hline 2.65 & 0.79 & 2.32 & 1.15 & 2.36 & 2.63 \\
\hline
\end{tabular}

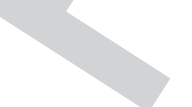

Models

Measured vs. mathematical

Measured vs. SAP2000

0.52
0.79

2.19

1.47
1.15

1.71
2.63 

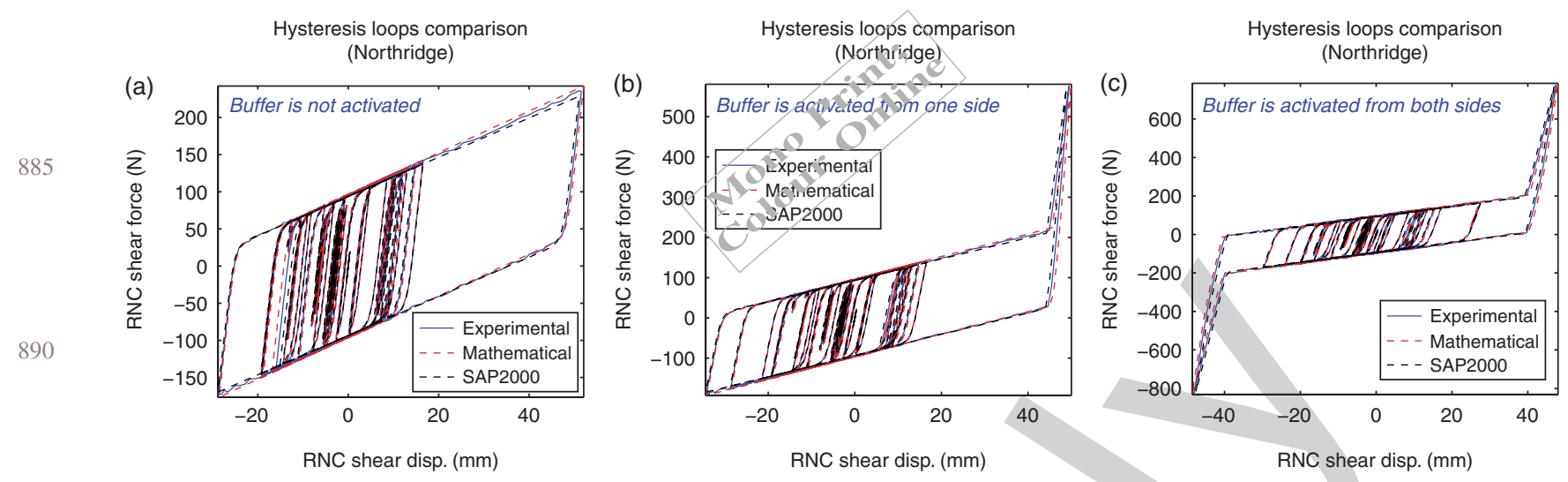

Figure 8. Experimental, analytical and SAP2000 force-displacement relationships comparison under reduced-amplitude Northridge excitation: (a) buffer mechanism is not activated; (b) buffer mechanism is activated from one side; (c) buffer mechanism is activated from both sides.

plotted in Figure 8. Figure 8(a)-(c) demonstrates the hysteresis loop shapes considering full buffer deactivation, buffer activation from one side and buffer activation from both opposite sides, respectively. According to Table 1 and Figure 8, the errors are effectively small enough to lead nearly to the same results considering any of the three RNC isolator models. Although the errors of both experimentally measured and mathematical approaches are smaller, using these two models is much more complicated and time-consuming than using the SAP2000 model. Therefore, regarding flexibility, versatility, computation efforts, ease of use and wide sets of users, the SAP2000 model could represent another more practical alternative to express the RNC isolator's behaviour without sacrificing or losing the modelling accuracy.

\section{Structural model}

Figure 9 shows a schematic diagram of the RNC-isolated linear multistory structure, which is surrounded with a fixed-base rigid U-shaped adjacent structure, for this study. The structure is a symmetric 3D building of five bays, each of $8.0 \mathrm{~m}$ span, with two end cantilevers, each of $2.5 \mathrm{~m}$ length, in both horizontal directions. It has eight floors plus the isolated base floor with a typical story height of $3.0 \mathrm{~m}$. The base-isolated building is modelled as a shear-type structure supported on 36 heavy load RNC isolators, Figure 1, one under each column. Each floor has two lateral displacement degrees of freedom (DOF) beside one rotational DOF around the vertical axis. The structure is excited by a single horizontal earthquake component at a time in XX and YY directions, separately.

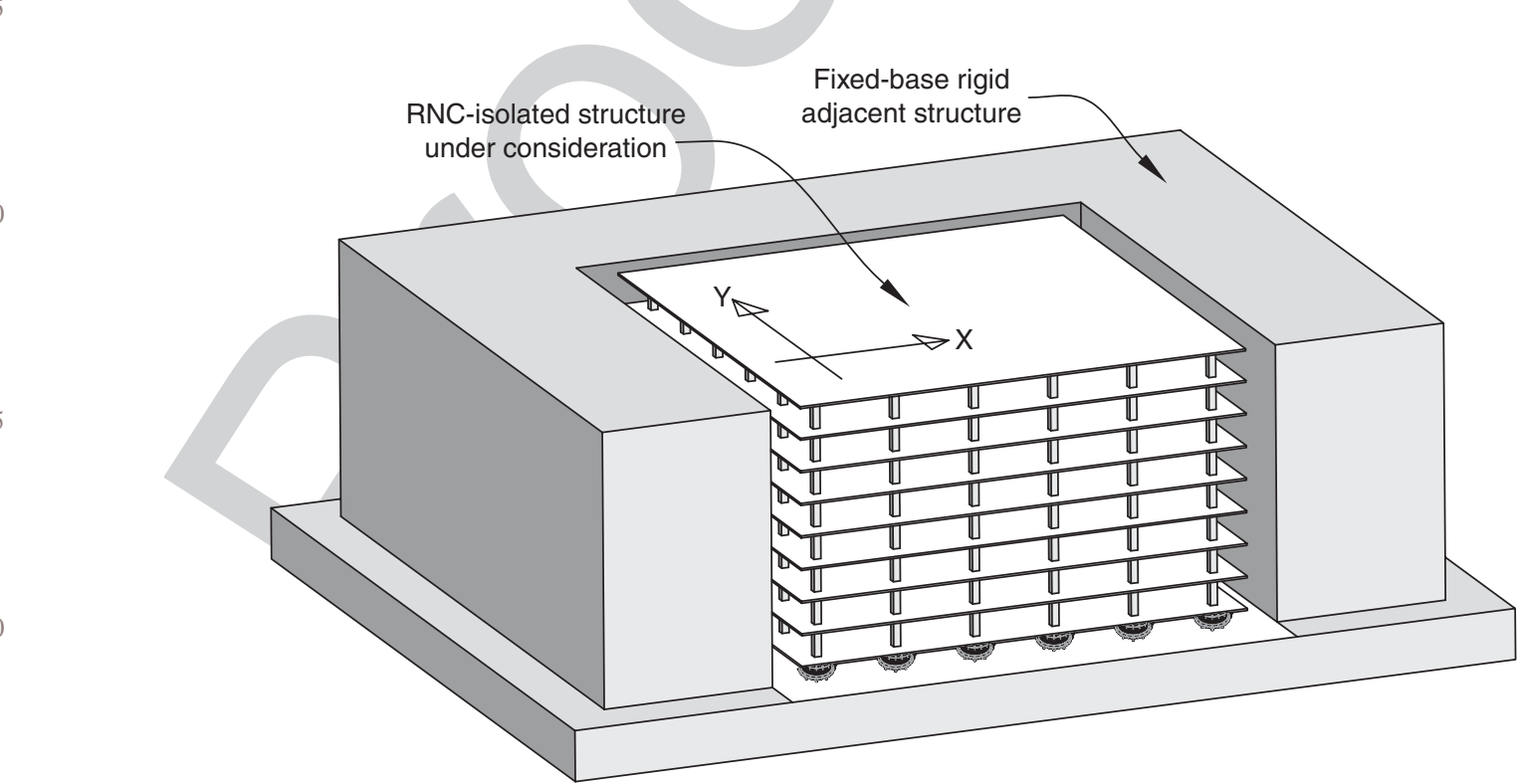


The superstructure is assumed to remain elastic during the earthquake excitation and impact phenomenon. The construction material of the isolated structure is normalweight reinforced concrete with a total material volume of $4068.36 \mathrm{~m}^{3}$, a total weight of $101,709.0 \mathrm{kN}$ and a total mass of $10,368 \mathrm{kN} \mathrm{s}^{2} \mathrm{~m}^{-1}$. The structural foundation is assumed to be rigid and supported on rocky soil. The fixedbase structure has a fundamental period of $0.436 \mathrm{~s}$ and modal frequencies of $2.29,6.80,11.06,14.94,18.29$,

$100021.02,23.03$ and $24.26 \mathrm{~Hz}$ for modes from one to eight, respectively. The structural damping ratio for all modes is fixed to $2.50 \%$ of the critical damping. This damping value is conservative in order to better judge the ability of the RNC isolator to improve the structural responses at low structural damping; in other words, to investigate the device effectiveness under harsh loading conditions and relatively small contribution of structural damping to the response improvement. The example structure is assumed to behave always elastically.

1010 To determine the seismic pounding forces between the considered structure and its surrounding adjacent one, a set of unidirectional nonlinear gap elements (available in SAP2000) are used at the topmost corresponding points at both structures. Each element has a certain gap input along the direction of its length, which is the same as the actual chosen seismic gap between structures. When the peak structural displacements exceed that gap in a certain direction, pounding will take place and then its value is estimated by the gap element in that direction. The gap

1020 elements output zero pounding as long as the peak structural displacements are lower than the chosen gap width.

Several RNC isolators are designed for this study. For example, one design is able to accommodate a travel 1025 design displacement, $x_{\mathrm{des}}$, of $650 \mathrm{~mm}$. Just after exceeding that selected $x_{\text {des }}$, the self-stopping (buffer) mechanism is directly activated to stop motion over a stopping distance $x_{\text {brake }}$. The stopping distance depends mainly on pounding force intensity, $F_{\mathrm{bB}}$, and the selected buffer stiffness $k_{\mathrm{b}}$. That designed RNC isolator example is $1.35 \mathrm{~m}$ high. The outer diameter of the upper and lower bearing steel plates is $2.43 \mathrm{~m}$. It is provided with 16 hysteretic mild steel dampers of the shape shown in Figure 1, each having a diameter of $40 \mathrm{~mm}$.

To enable adequate vertical load capacity, the RNC isolator is provided with a linear hollow elastomeric cylinder around the rolling core to represent the main vertical load-carrying capacity, while the rolling core itself works as a secondary vertical support in this case. The inner and outer diameters of the hollow elastomeric cylinder are 1.73 and $2.33 \mathrm{~m}$, respectively. This linear elastomeric part was initially designed to follow some available recommendations of the Uniform Building Code (UBC, 1997) and American Association of State Highway and Transportation Officials (AASHTO LRFD, 2005), to provide a minimum vertical load capacity of $4000.0 \mathrm{kN}$ at the extreme deformed position of buffer and to provide times that capacity at neutral or less deformed positions.

The designed RNC isolators for this study may be seen large but their chosen dimensions allow for a really big peak horizontal displacement of $650 \mathrm{~mm}$ under ground motions. Such dimensions are nearly linearly proportional to the requested peak displacement or design displacement of the RNC isolator, after which its inherent buffer mechanism is activated. For example, all dimensions could be reduced to almost one-half if the peak horizontal displacement of the RNC isolator was set to $325 \mathrm{~mm}$ instead of $650 \mathrm{~mm}$. A stiff upper isolated base slab with inverted girders could account for the difference in dimensions between the columns and the device. The device requires monitoring after each excitation, especially the metallic yield dampers. However, the experimental testing of the RNC isolator (Ismail \& Rodellar, 2014b) showed that metallic yield dampers could last for several hours under continuous shaking without damage

\section{NF earthquakes}

NF ground motion are characterised by one or more intense long-period velocity and displacement pulses that can lead to a large isolator displacement (Jangid \& Kelly, 2001; Murat \& Srikanth, 2007). Therefore, three NF ground motions of different intensities, velocity and displacement pulses are considered to evaluate the performance of the RNC isolator's self-stopping (buffer) mechanism. These NF ground motions were obtained from the near-most stations to the fault rupture, with intensities that range from $0.27 \mathrm{~g}$ to $1.23 \mathrm{~g}$ to represent relatively low to severe intensity $\mathrm{NF}$ earthquakes. The peak ground accelerations (PGA), velocities (PGV) and displacements (PGD) against their corresponding time instants of each ground motion are listed in Table 2. On measuring the intensity of NF ground motions (Makris \& Black, 2004), revealed that the PGA is a better representative intensity measure than the PGV. Accordingly, the used NF ground motions are sorted by their PGA in an ascending order.

Another measure of the ground motion characteristics is through comparing their response spectra. Figure 10 compares the acceleration, velocity and displacement response spectra of the used three NF ground motions as well as the mean spectrum in each case. Figure 10(a),(b) justifies the selection of an example structure with a fundamental period less than $0.50 \mathrm{~s}$. Such selection produces high structural responses under the three NF earthquakes because of high spectral accelerations and velocities within that zone. This provides a challenging situation to examine the proposed solution of response improvement using the $\mathrm{RNC}$ isolator. 
Table 2. Main characteristics of the NF ground motions used in this study.

1105

Although the NF earthquakes are characterised by having large vertical accelerations, those acceleration components are not considered in this study. The reason beyond neglecting the vertical acceleration components 1120 is that they will have minor contribution to the peak horizontal structural displacements, especially in the case of symmetric structures as in this paper. Therefore, such acceleration components will not influence the seismic gaps determination nor the lateral seismic behaviour of closely spaced structures, which is the objective of this paper.

\section{Pounding of fixed-base adjacent structures}

The RNC isolator's buffer intends to draw any possible seismic pounding down to the isolation level to be only within the bearing bounds, keeping the isolated structure always distant from direct pounding contact with adjacent structures. Therefore, there is a need to investigate the influence of changing pounding location, from top to bottom along the structure height, on the structural response and to study how pounding could negatively affect a structure in general. For this reason, a series of dynamic analyses has been conducted in order to investigate the case of having a fixed-base building adjacent to other rigid fixed-supported buildings of different heights, to exhibit direct structure-to-structure pounding at different floor heights and from one or two opposite sides. Another objective of this study is to use its results as a reference of comparison with those results of Section 7.

\subsection{Influence of pounding location on structural response}

Figure 11 shows eight different loading cases, of the example structure of Figure 9, for consideration in this section as a fixed-base structure. In addition, four more similar structures are considered but with different mass and stiffness properties to introduce the effects of variable structural mass and stiffness. The seismic gap is chosen as $30.0 \mathrm{~mm}$ to achieve structural pounding in almost all cases under the three real NF earthquakes of Table 2. Using the nonlinear time-history analysis, the obtained results are listed in Tables 3 considering that all structures behave linearly before pounding and remain elastic after pounding. In each load case of Figure 11, the topmost floor or plan of the rigid adjacent variable-height structures (plotted in solid grey) is connected to the corresponding floor of the example structure, at the same height, through a set of six horizontal, unidirectional and nonlinear gap elements having a horizontal stiffness of $25 \mathrm{e} 5 \mathrm{kN} / \mathrm{m}$ to account for seismic pounding of structures.

In addition to the pounding severity, the peak absolute structural acceleration acceleration ratio is considered as a performance measure because a sudden stopping of displacement at the pounding level results in large and quick acceleration pulses in the opposite direction. Such acceleration ratio represents the quotient of peak absolute accelerations just after and before pounding. The highlighted acceleration ratios of Table 4, in bold italic fonts, indicate that the peak absolute acceleration after pounding takes place at the topmost floor, whereas the other values means that the peak absolute acceleration is located at a different floor where pounding occurs. Both of structural pounding severity and acceleration ratio, in this section, are referred to as the structural response. Based on Tables 5, the main observations are as follows:

- The earthquake-induced pounding is unfavourable for a structure, as it significantly increases the peak absolute floor accelerations and, therefore, increases obviously the structural capacity demand.

- The vertical location of pounding and/or being from one or two opposite sides influence significantly the distribution of story peak responses and pounding intensity through the building height. At the same lateral stiffness of an adjacent structure, the worst influence of pounding on structural responses arises 


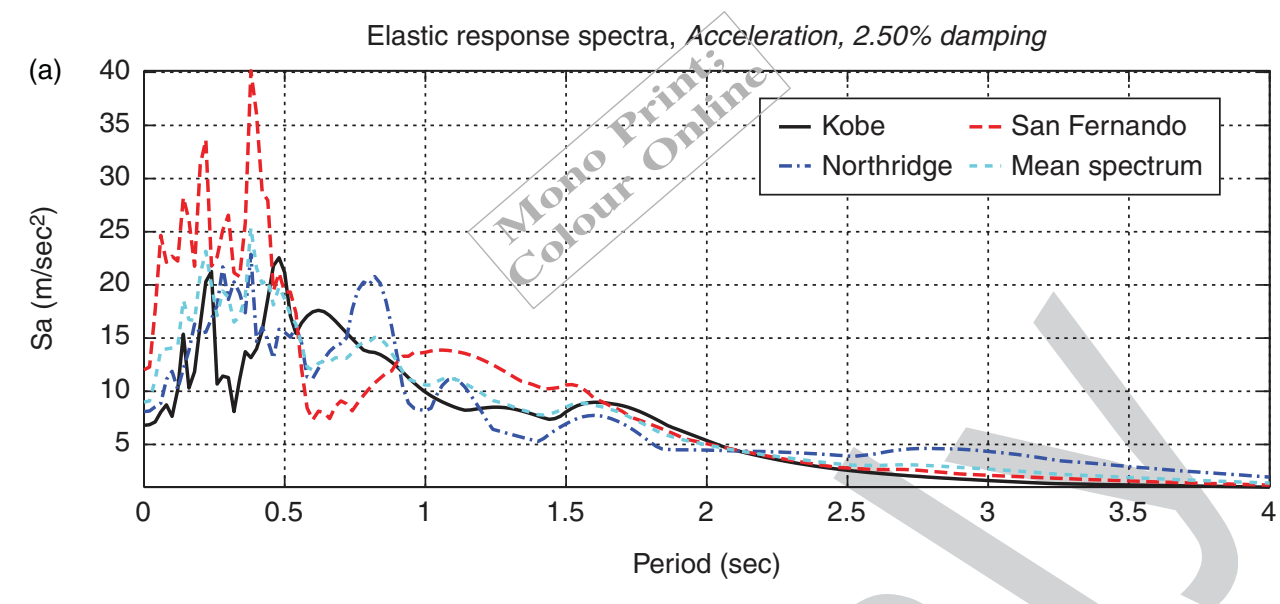

Elastic response spectra, Acceleration, 2.50\% damping

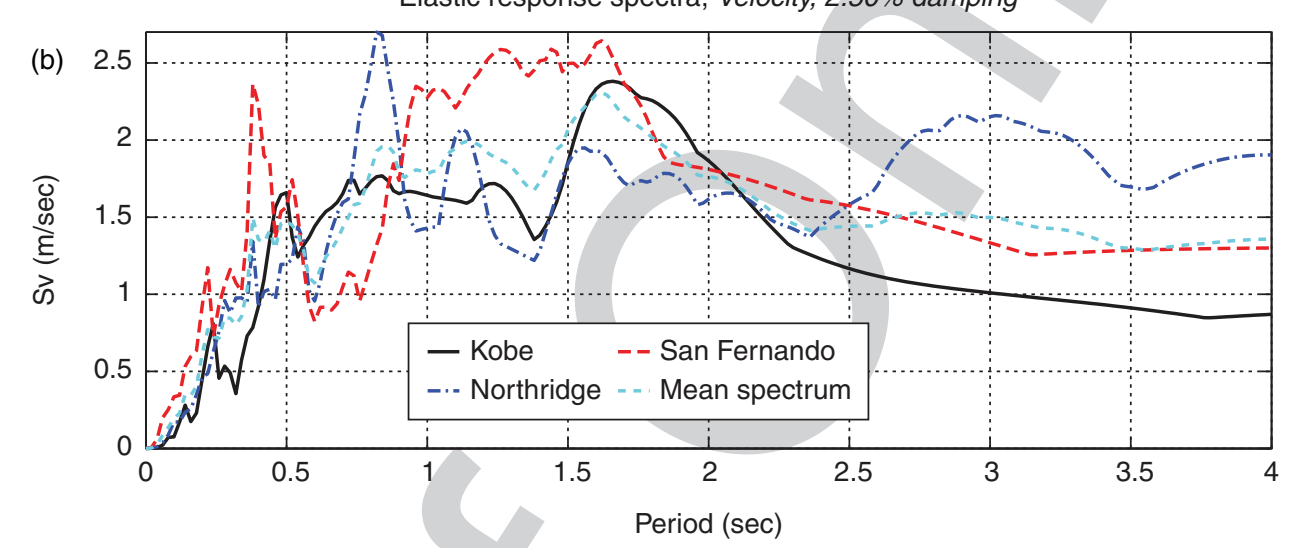

Elastic response spectra, Displacement, 2.50\% damping

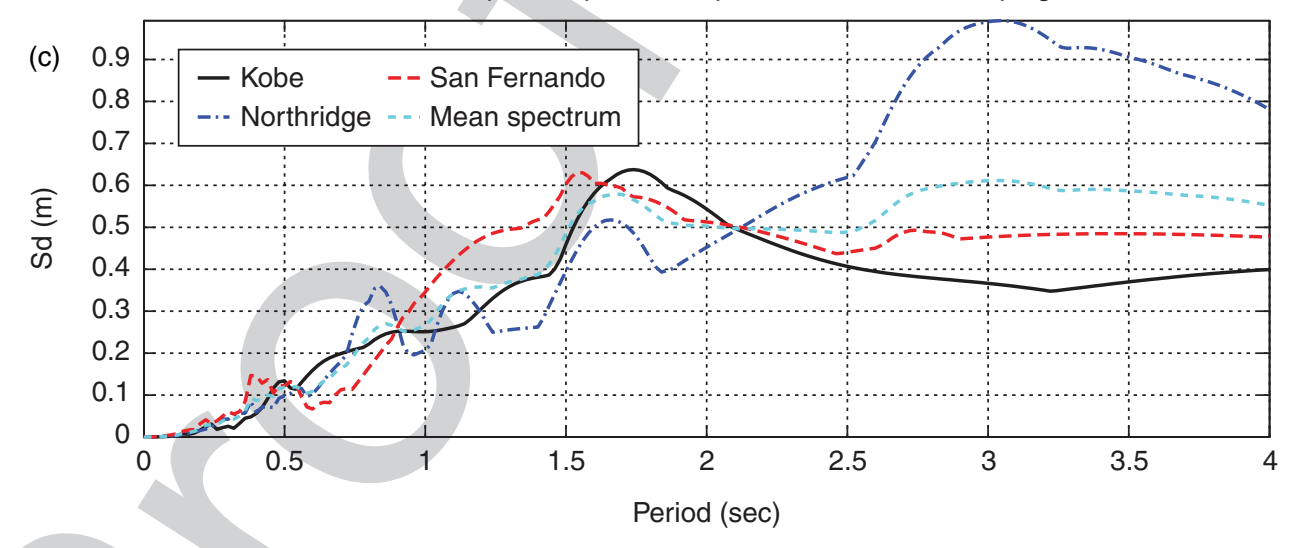

Figure 10. Elastic response spectra of the used NF ground motions.

when it takes place within the upper two-thirds of the structure height, while significantly less amplified structural responses become apparent, in most cases, as pounding occurs at the lower third of structure height. In addition, single-side pounding is more severe than double-side pounding and leads to higher acceleration responses, especially in flexible and heavy mass structures.

- The peak structural responses due to pounding are usually located within the top third of structure height, particularly the topmost floor as in stiff structures, except the cases of heavy mass and flexible structures where the amplified peak responses are worse and take place at the pounding floor level.

- Pounding severity is sensitive to even relatively small variations of structural mass and stiffness properties as well as the excitation characteristics, leading to notable variations of amplified structural responses. At the same seismic gap, both flexible 
NSIE 993660—26/12/2014—MOHANRAJ.D—501567—-Style 4

Structure and Infrastructure Engineering

Fixed-base structure

Case 1: direction $X-X$

Pounding at $8^{\text {th }}$ floor

Double-side pounding

1325

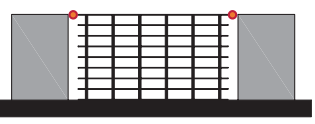

Fixed-base structure Case 5: direction Y-Y Pounding at $8^{\text {th }}$ floor One-side pounding

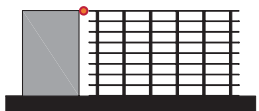

Fixed-base structure

Case 2: direction $X-X$

Pounding at $6^{\text {th }}$ floor

Double-side pounding

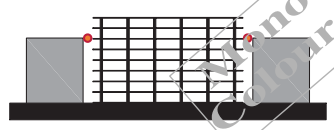

Fixed-base structure Case 6: direction $Y-Y$

Pounding at $6^{\text {th }}$ floor

One-side pounding

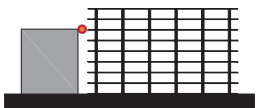

Fixed-base structure

Case 3: direction $X-X$

Ruunding at $4^{\text {th }}$ floor

Doúble-side pounding

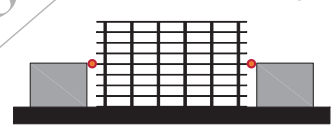

Fixed-base structure

Case 7: direction Y-Y

Pounding at $4^{\text {th }}$ floor

One-side pounding
Fixed-base structure

Case 4: direction X-X

Pounding at $2^{\text {nd }}$ floor

Double-side pounding

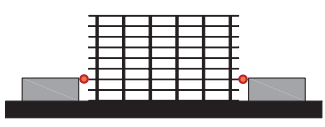

Fixed-base structure

Case 8: direction Y-Y

Pounding at $\mathbf{2}^{\text {nd }}$ floor

One-side pounding
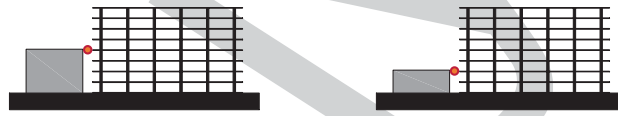

Figure 11. Different considered cases of study regarding possible pounding levels and directions using a fixed-base structure surrounded with adjacent rigid structures.

and heavy mass structures are more susceptible to severe pounding, with adjacent strictures, than stiffer and lighter mass structures. Moreover, the peak displacement and velocity pulses of ground motion could significantly influence pounding severity and structural response amplification, sometimes, more than the PGA itself.

- Pounding is a highly nonlinear phenomenon and

Table 3. Structural response quantities, the case of fixed-base structure $(\mathrm{kN}, \mathrm{m}, \mathrm{s})$.

Fixed-base structures

\begin{tabular}{lc}
\hline Kobe earthquake & \\
\hline & $\begin{array}{c}\text { Structural } \\
\text { pounding } \\
\text { force } \\
(\mathrm{kN})\end{array}$
\end{tabular}

\begin{tabular}{cc} 
Fixed-base structures \\
\hline Northridge earthquake \\
\hline & Structural \\
pounding \\
Acceleration & force \\
ratio & $(\mathrm{kN})$
\end{tabular}

$\mathbf{2 5 \%}$ lighter structure, fundamental vibration period $=0.37784 \mathrm{~s}$

$\begin{array}{lrr}\text { cture, fundamental vibration period }=0.37784 \mathrm{~s} \\ \mathbf{4 . 1 5} & 70,440 & \mathbf{5 . 1 7} \\ 3.18 & 67,440 & \mathbf{3 . 1 8} \\ 2.06 & 40,860 & 3.08 \\ \mathbf{1 . 0 0} & 0 & 2.49 \\ \mathbf{5 . 4 3} & 92,340 & \mathbf{3 . 7 2} \\ \mathbf{3 . 3 5} & 85,320 & 3.12 \\ 1.95 & 38,520 & 2.72 \\ \mathbf{1 . 0 0} & 0 & 1.77\end{array}$

Normal weight structure, fundamental vibration period $=0.436 \mathrm{~s}$

$1 \quad \mathbf{4 . 0 5} \quad 147,120 \quad \mathbf{4 . 6 4}$

$3.17-118,020$

$\begin{array}{lll}3 & 3.40 & 112,440\end{array}$

$\begin{array}{lll}4 & 2.07 & 45,960\end{array}$

$\begin{array}{llll}5 & \mathbf{4 . 3 6} & \mathbf{4 3 8 , 3 6 0} & \mathbf{4 . 8 5}\end{array}$

2.56

4.07

4.17

2.89

3.16

3.09
181,440

139,440

153,660

174,180

203,760

168,780

\subsection{7}

6.74

3.72

3.50

4.75

3.78

2.81

141,240

135,960
104,880
99,960
55,260
102,060
106,920
89,580
42,660

153,540
163,740
113,100
29,280
140,520
211,440
101,340
18,780

140,940
203,160
110,580
81,180
129,300
134,280
100,020
73,980

San Fernando earthquake

\begin{tabular}{cc}
\hline & $\begin{array}{c}\text { Structural } \\
\text { pounding } \\
\text { force } \\
\begin{array}{c}\text { Acceleration } \\
\text { ratio }\end{array}\end{array}$ \\
\end{tabular}

1.88

1.83

1.47

2.87

2.75

1.79

1.55

2.36

2.35

3.10

3.05

3.77

4.15

2.80

3.11

2.00

2.94

3.70

3.17

3.46

5.73

4.37

3.09

2.45
95,700

128,040

93,300

109,140

113,160

143,040

111,180

111,060

151,320

203,100

244,980

210,420

238,260

252,240

259,680

137,400

214,800

241,740

304,920

187,800

270,360

300,960

188,220

142,500 
NSIE 993660—26/12/2014—MOHANRAJ.D—501567—-Style 4

Table 4. Structural response quantities the case of fixed-base structure (kN, m, s).

1435

1440

Table 5. Influence of gap width on structural acceleration and pounding intensity, case of fixed-base structure ( $\mathrm{kN}, \mathrm{m}, \mathrm{s})$.

Fixed-base structures, Kobe earthquake

\begin{tabular}{|c|c|c|c|c|c|c|c|c|}
\hline \multirow[b]{2}{*}{ Case } & \multicolumn{2}{|c|}{ Gap $=25 \% x_{n-\max }$} & \multicolumn{2}{|c|}{ Gap $=\mathbf{5 0} \% x_{n-\max }$} & \multicolumn{2}{|c|}{ Gap $=\mathbf{7 5} \% x_{n-\max }$} & \multicolumn{2}{|c|}{ Gap $=\mathbf{9 5} \% x_{n-\max }$} \\
\hline & $\begin{array}{l}\text { Accel. } \\
\text { ratio }\end{array}$ & $\begin{array}{c}\text { Structural } \\
\text { pounding } \\
\text { force } \\
(\mathrm{kN})\end{array}$ & $\begin{array}{l}\text { Accel. } \\
\text { ratio }\end{array}$ & $\begin{array}{l}\text { Structural } \\
\text { pounding } \\
\text { force } \\
(\mathrm{kN})\end{array}$ & $\begin{array}{l}\text { Accel. } \\
\text { ratio }\end{array}$ & $\begin{array}{l}\text { Structural } \\
\text { pounding } \\
\text { force } \\
(\mathrm{kN})\end{array}$ & $\begin{array}{l}\text { Accel. } \\
\text { ratio }\end{array}$ & $\begin{array}{c}\text { Structural } \\
\text { pounding } \\
\text { force } \\
(\mathrm{kN})\end{array}$ \\
\hline 1 & 4.71 & 130,800 & 4.30 & 116,640 & 4.85 & 106,620 & 2.41 & 41,100 \\
\hline 2 & 1.57 & 89,760 & 2.02 & 94,440 & 2.72 & 104,460 & 1.48 & 40,020 \\
\hline 3 & 2.37 & 12,3300 & 2.44 & 99,120 & 2.26 & 82,320 & 1.14 & 30,420 \\
\hline 4 & 1.83 & 82,920 & 2.14 & 81,840 & 1.39 & 45,960 & 1.03 & 24,660 \\
\hline 5 & 5.00 & 138,780 & 5.18 & 120,960 & 3.40 & 102,780 & 1.89 & 30,660 \\
\hline 6 & 2.61 & 124,140 & 2.74 & 109,800 & 2.53 & 103,920 & 1.29 & 34,860 \\
\hline 7 & 2.69 & 109,800 & 2.73 & 91,860 & 1.96 & 75,360 & 1.00 & 31,380 \\
\hline 8 & 1.98 & 96,300 & 1.82 & 65,880 & 1.17 & 39,960 & 1.00 & 23,580 \\
\hline
\end{tabular}

Structural pounding $(\mathrm{kN})$

\begin{tabular}{|c|c|c|c|c|c|c|}
\hline \multicolumn{7}{|c|}{ Less stiff structure, fundamental vibration period $=0.575 \mathrm{~s}$} \\
\hline 1 & 5.90 & 157,980 & 5.78 & 130,020 & 9.92 & 210,360 \\
\hline 2 & 6.42 & 164,280 & 4.53 & 128,520 & 6.03 & 167,280 \\
\hline 3 & 6.32 & 169,620 & 4.08 & 142,740 & 6.65 & 217,560 \\
\hline 4 & 3.66 & 95,820 & 4.82 & 116,880 & 1.20 & 26,820 \\
\hline 5 & 6.50 & 175,980 & 6.67 & 141,840 & 10.38 & 252,720 \\
\hline 6 & 7.02 & 222,300 & 5.11 & 146,400 & 8.32 & 242,040 \\
\hline 7 & 5.16 & 192,360 & 5.69 & 143,100 & 9.51 & 239,400 \\
\hline 8 & 2.79 & 94,440 & 2.93 & 72,780 & 1.00 & 13,380 \\
\hline \multicolumn{7}{|c|}{ Normal stiffness structure, fundamental vibration period $=0.436 \mathrm{~s}$} \\
\hline 1 & 4.05 & 147,120 & 4.64 & 153,540 & 2.35 & 151,320 \\
\hline 2 & 3.17 & 118,020 & 5.29 & 163,740 & 3.10 & 203,100 \\
\hline 3 & 3.40 & 112,440 & 4.17 & 113,100 & 3.05 & 244,980 \\
\hline 4 & 2.07 & 45,960 & 1.43 & 29,280 & 3.77 & 210,420 \\
\hline 5 & 4.36 & 138,360 & 4.85 & 140,520 & 4.15 & 238,260 \\
\hline 6 & 2.87 & 106,440 & 5.56 & 211,440 & 2.80 & 252,240 \\
\hline 7 & 2.99 & 98,340 & 3.58 & 101,340 & 3.11 & 259,680 \\
\hline 8 & 1.17 & 39,960 & 1.12 & 18,780 & 2.00 & 137,400 \\
\hline \multicolumn{7}{|c|}{ More stiff structure, fundamental vibration period $=0.346 \mathrm{~s}$} \\
\hline 1 & 1.60 & 35,209 & 5.36 & 153,304 & 3.27 & 121,680 \\
\hline 2 & 1.57 & 36,540 & 3.99 & 135,720 & 4.21 & 211,740 \\
\hline 3 & 1.27 & 20,820 & 2.54 & 100,320 & 1.50 & 67,500 \\
\hline 4 & 1.00 & 0 & 1.00 & 0 & 1.03 & 29,940 \\
\hline 5 & 3.34 & 74,100 & 4.06 & 135,360 & 2.83 & 110,760 \\
\hline 6 & 2.66 & 72,120 & 3.58 & 129,180 & 2.93 & 153,060 \\
\hline 7 & 1.27 & 20,820 & 2.83 & 99,180 & 1.97 & 90,300 \\
\hline 8 & 1.00 & 0 & 1.00 & 0 & 1.03 & 29,940 \\
\hline
\end{tabular}


represents a severe load condition that could result in significant structural damage. In addition, the amplified acceleration response at the pounding level indicates that pounding is especially harmful for sensitive equipment or secondary systems having short periods.

\subsection{Influence of gap width on structural response}

The effects of variation in seismic gap distance on superstructure peak acceleration and pounding severity are studied under the NF Kobe earthquake considering a rigid surrounding adjacent structure of variable height, according to the eight cases of Figure 11. The responses are obtained by varying the gap distance at pounding levels, where the seismic gaps are taken $25 \%, 50 \%, 75 \%$ and $95 \%$ of the peak displacement response at the pounding level $x_{n-\max }$. The results of this study are presented in Table 2, where the main observations are as follows:

- There is an initial increase in acceleration ratio at the topmost floor up to a certain value of separation gap distance and it decreases with further increase in the gap distance. On the other hand, pounding intensity becomes less severe as the separation seismic gap increases.

- Similar to the acceleration ratio, double-side pounding is a bit more severe than single-side pounding at smaller seismic gaps, while single-side pounding becomes more severe than the double-side one as the separation seismic gap increases.

- If there is no practical space limitation, increasing the seismic gap width represents an effective solution to avoid or at least minimise structural response magnification and the possibly resulting damage.

\section{Pounding of an RNC-isolated structure with adjacent structures}

In this section, the RNC isolator is presented as an alternative solution of seismic isolation under $\mathrm{NF}$ ground motions considering limited seismic gaps using the RNCisolated structure of Figure 9. The integrated buffer mechanism and the non-expensive source of high damping

1585 together with being rolling-based allow the RNC isolator to compromise between the peak structural acceleration and displacement besides the peak bearing displacement itself. Using the nonlinear time-history analysis, this study first investigates the ability of the RNC isolator's buffer to 1590 limit lateral bearing displacement in Section 7.1. Then, the RNC isolator ability to limit pounding with adjacent structures is explored in Section 7.2. After that, the influence of RNC isolator's buffer on isolated structural responses is considered in Section 7.3. Finally, the study attempts to find the appropriate RNC isolator character- istics for NF isolation with limited seismic gaps in Section 7.4. The RNC-isolated structure is excited only in the X direction by a single unidirectional ground motion component at a time, to focus on double-side pounding in this section.

\subsection{Ability of RNC isolator's buffer to limit lateral bearing displacement}

From this section on, all features of the RNC isolator listed in Sections 3 and 3.1 are incorporated into the carried out nonlinear time-history analyses. This section presents and discusses the results of 336 case studies of the RNCisolated structure, of Figure 9, regarding the influence of $\mathrm{RNC}$ isolator's design displacement, buffer stiffness and separation seismic gap on the peak bearing, or isolated base, displacement. Under Northridge earthquake, the 3D bar plots of Figure 12 illustrate the variation of peak bearing displacement considering four main $\mathrm{RNC}$ isolator designs having design displacements of 20,30, 40 and $50 \mathrm{~cm}$ in Figure 12(a)-(d), respectively. In each figure, the separation seismic gap extends from the corresponding isolator's design displacement up to $66 \mathrm{~cm}$, which represents the maximum unsafe seismic gap that still permits pounding of the RNC-isolated structure with the adjacent rigid structure, having the same height, under the selected NF earthquake.

Figure 12 demonstrates that the RNC isolator is able to limit the peak bearing displacements to the preselected design displacements at high values of buffer stiffness. The influence of seismic gap distance on the peak bearing displacement appears only at low values of buffer stiffness and then becomes invisible as the buffer stiffness increases. At lower seismic gaps, the peak RNC isolator displacement is relatively low and increases with the increase in seismic gaps at relatively low values of the buffer stiffness, particularly, at smaller design displacements of the RNC isolator as in Figure 12(a),(b). Both buffer stiffness and seismic gap have no influence on the peak bearing displacement as the former exceeds $1 \mathrm{e} 6 \mathrm{kN} /$ $m$, which is a common observation of Figure 12(a)-(d).

\subsection{Ability of RNC isolator to limit pounding with adjacent structures}

The main consequence of successfully limiting the peak bearing displacement to a preselected isolator design displacement is increasing the separation seismic gap between the RNC-isolated structure's topmost floor and the adjacent structure. Such result could be particularly useful in the case of having limited or insufficient seismic gaps that cannot accommodate the peak relative displacement response of both adjacent structures. As a result, this should eliminate partially, or even entirely, the pounding contact between both closely spaced adjacent 


\section{(19)}

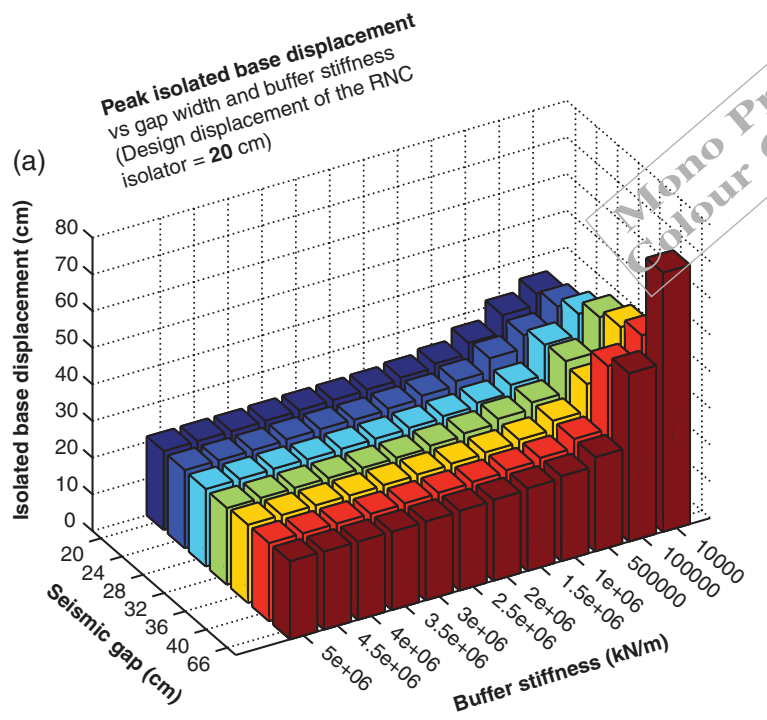

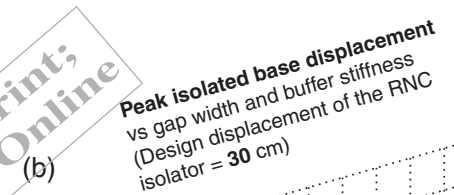

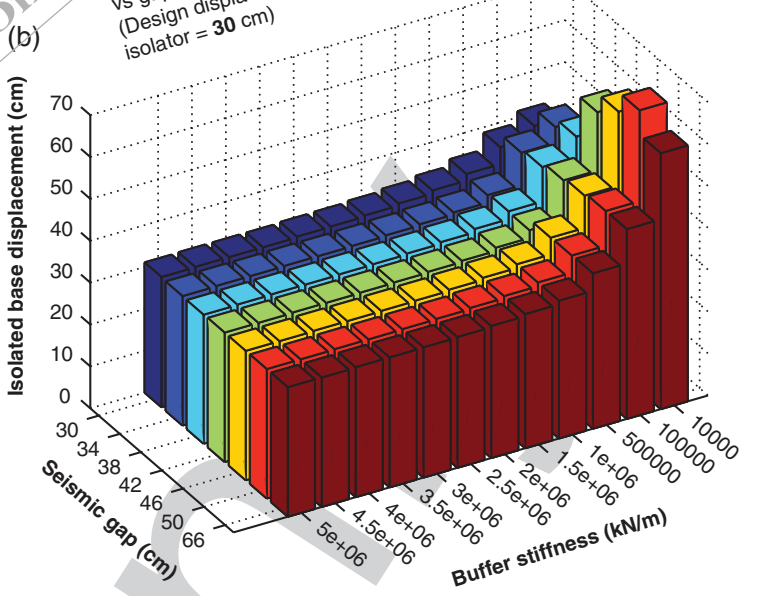

Figure 12. Peak RNC-isolated base displacement against seismic gap width and buffer stiffness for different isolator's design displacements of (a) $20 \mathrm{~cm}$; (b) $30 \mathrm{~cm}$; (c) $40 \mathrm{~cm}$; (d) $50 \mathrm{~cm}$, under Northridge earthquake.

structures or at least minimises the possible pounding intensity between them. Figure 13 shows the peak RNCisolated structure's pounding forces with the adjacent rigid structure, which correspond to those results of

Fis design displacements of 20,30,40 and $50 \mathrm{~cm}$, respectively. Such peak pounding values are significantly higher than those of the fixed-base structure, in Section 6, due to the higher kinetic energy of the isolated structure just before impact.

However, it seems obvious that the RNC isolator has completely eliminated pounding between adjacent structures at $55 \%, 64 \%, 85 \%$ and $89 \%$ of the maximum unsafe seismic gap of $66 \mathrm{~cm}$, at RNC design displacements of 20, 30,40 and $50 \mathrm{~cm}$, respectively. Moreover, and just before entire elimination of structure pounding, the peak pounding intensity seems to decrease with the increase in buffer stiffness, separation seismic gap and the RNC design displacement, mainly at relatively low design displacement as in Figure 13(a)-(c). According to Figure 13(a)-(c), the trend of the RNC-isolated structure's pounding seems to decrease as the RNC isolator's design displacement increases before entire elimination of RNC-isolated structure pounding, but it starts to increase again at bigger design displacement as demonstrated by Figure 13(d). This result is not exactly similar to the corresponding trend of structure pounding in Section 6.2, which tends to always decrease with the increase in seismic gap.

The corresponding inner pounding of an RNC isolator is shown in Figure 14(a)-(d) at RNC design displacements of 20,30, 40 and $50 \mathrm{~cm}$, respectively. This inner pounding 
1765
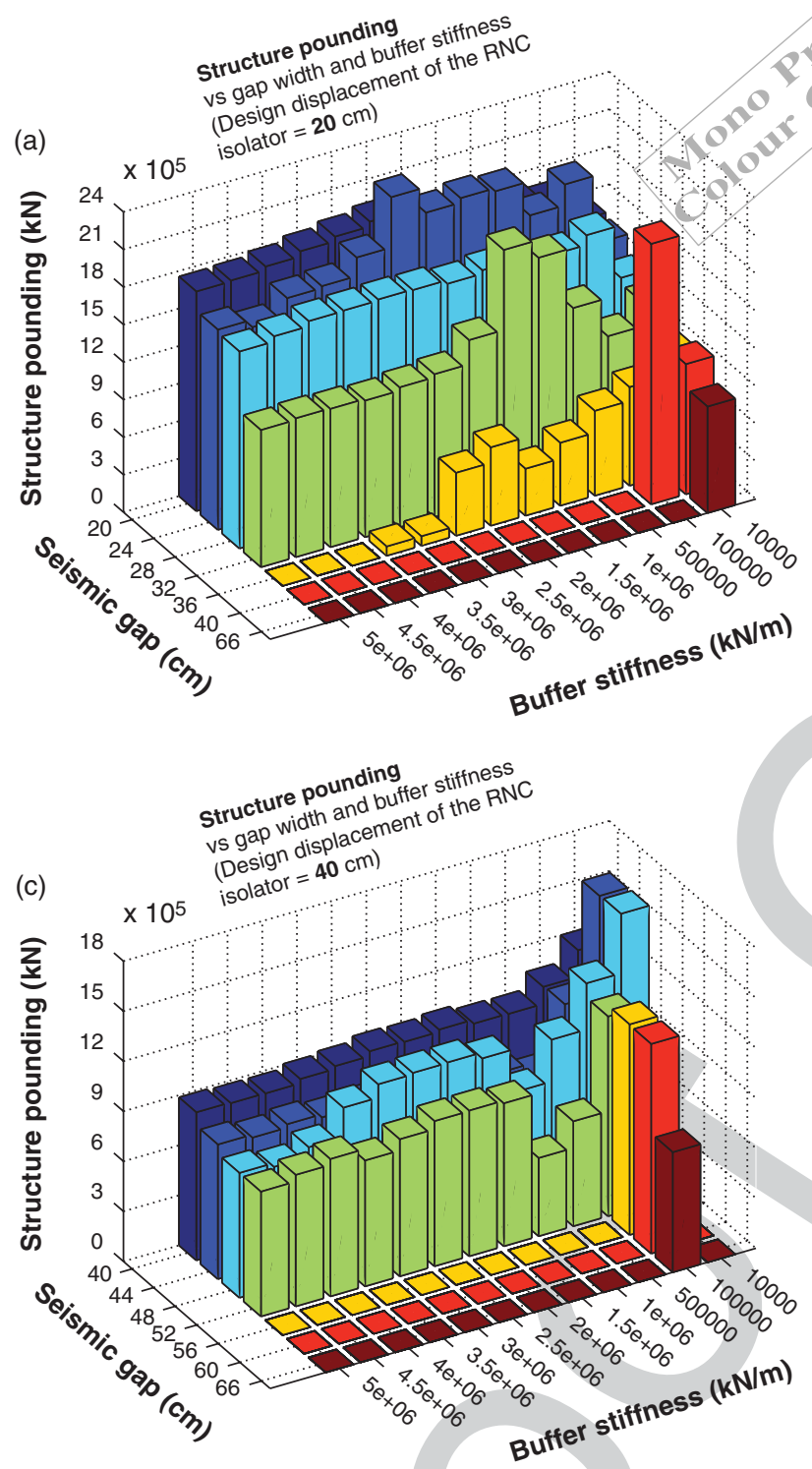

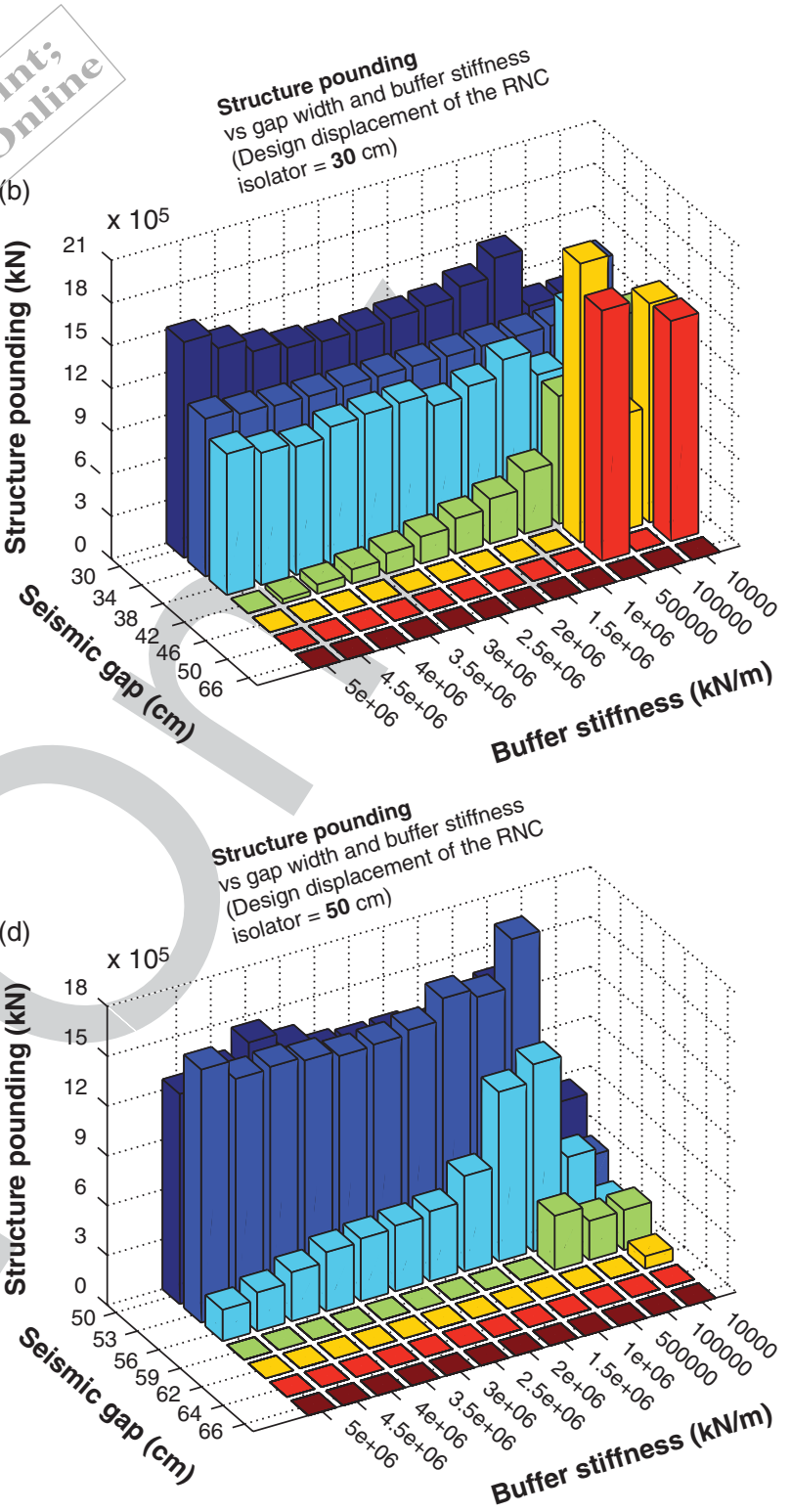

1825

Figure 13. Peak RNC-isolated structure pounding, at the topmost floor, against seismic gap width and buffer stiffness for different isolator's design displacements of (a) $20 \mathrm{~cm}$; (b) $30 \mathrm{~cm}$; (c) $40 \mathrm{~cm}$; (d) $50 \mathrm{~cm}$, under Northridge earthquake.

represents the main, unfavourable, direct result of activating the RNC isolator's buffer mechanism, just after exceeding a preselected design displacement. The other, favourable, result of buffer activation is certainly the partial or full elimination of an RNC-isolated structure with the closely spaced adjacent structures. Based on those figures, the main observations are as follows:

- The inner RNC isolator pounding increases with the increase in buffer stiffness before and after getting rid of structure pounding.

- Before removal of structure pounding, the RNC isolator's inner pounding decreases with the increase in the separation seismic gap, but it remains unchanged after structure pounding elimination even with further increase in seismic gap.

- The RNC isolator's inner pounding seems to decrease as its design displacement increases, particularly before entire elimination of RNCisolated structure pounding as illustrated in Figure 14(a)-(c), but it starts to increase again at bigger design displacement as in Figure 14(d).

- Although the inner pounding of an RNC isolator may approach the overall structure pounding of some cases in Section 6, the activation of the RNC isolator's buffer offers more critical advantages. For example, it is not only able to minimise or even prevent direct structure-to-structure pounding, and consequently the 
1875
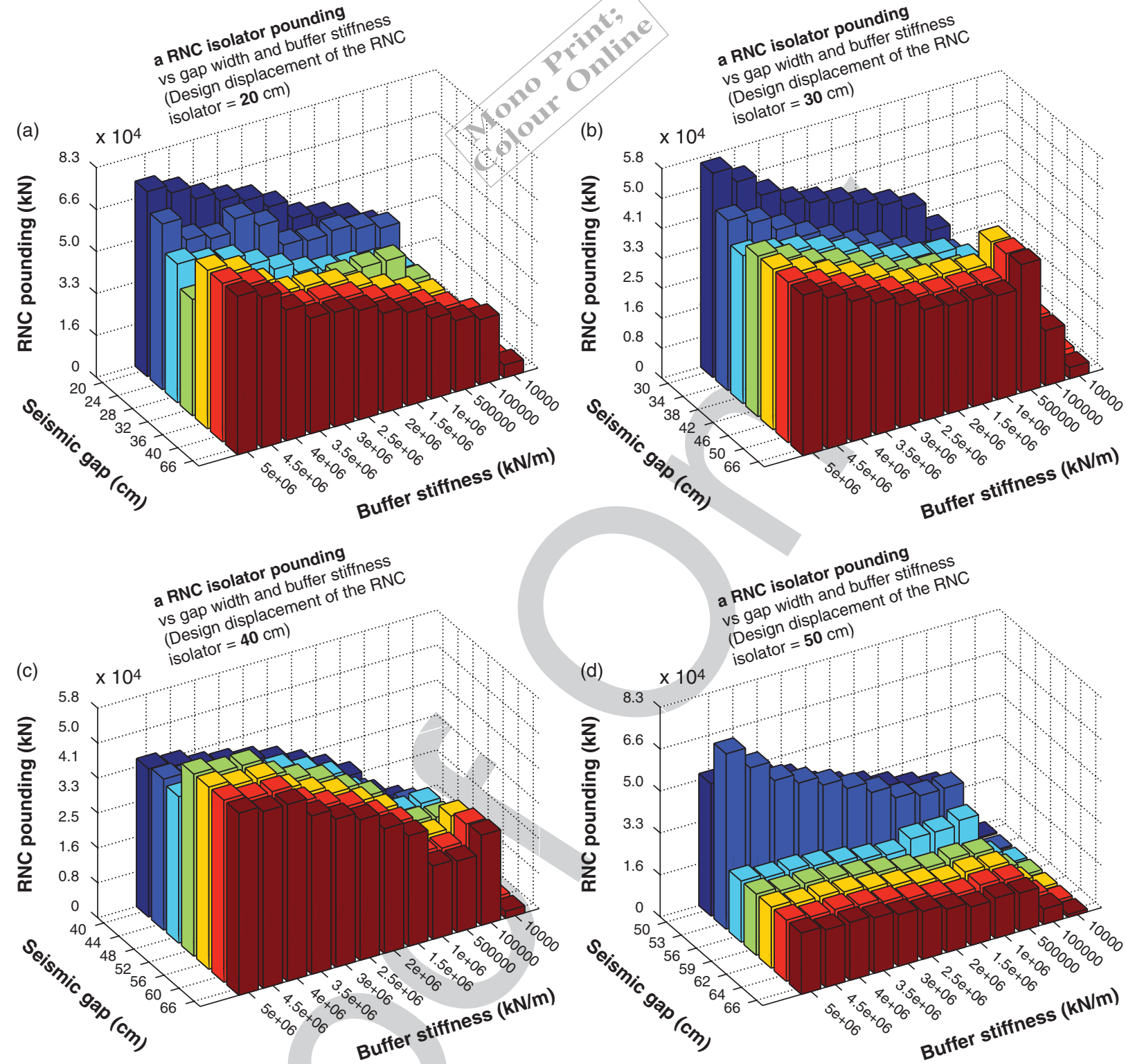

Figure 14. Peak RNC isolator's inner pounding against seismic gap width and buffer stiffness for different isolator's design displacements of (a) $20 \mathrm{~cm}$; (b) $30 \mathrm{~cm}$; (c) $40 \mathrm{~cm}$; (d) $50 \mathrm{~cm}$, under Northridge earthquake.

possibly resulting severe local or global structural and non-structural damages, but it also distributes pounding regularly on the isolated base floor in-plan area and keeps pounding always within the solid metallic body of the RNC isolator. Therefore, the RNC isolator's buffer could always prevent direct structure-to-structure pounding contact.

\subsection{Influence of RNC isolator's buffer on isolated structural responses}

This section investigates the main impact of partial or entire elimination of the RNC-isolated structure's pounding, with adjacent structure, on its response. Figure 15 shows the variation of peak ratios of four structural response quantities against the RNC isolator's design displacement and its buffer stiffness. In this section, a peak ratio represents the quotient of a peak response quantity of the RNC-isolated structure after pounding and the corresponding peak response value of a fixed-base structure with no pounding. The only source of pounding in this section results from the activation of the RNC isolator buffer mechanism, where a sufficiently wide seismic gap is selected to prevent structure-to-structure pounding.

Figure 15(a),(b) illustrates how pounding deteriorates the isolation efficiency, regarding the peak absolute 
1985 (a)
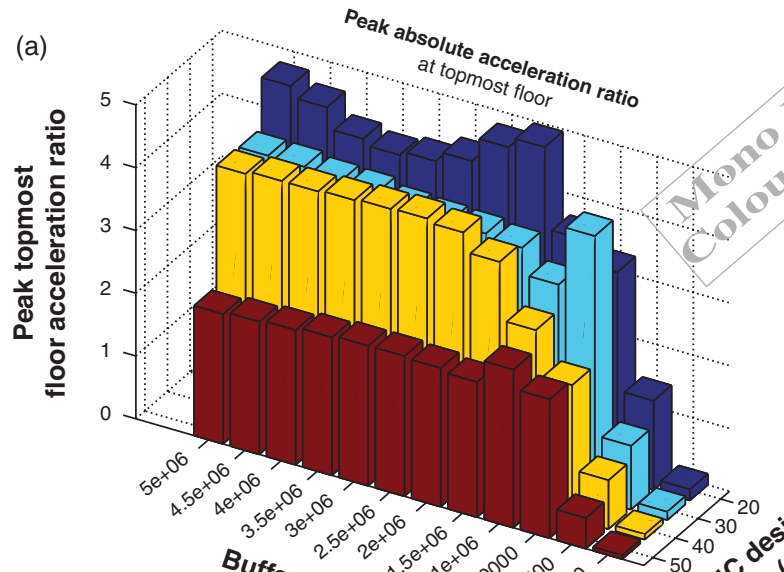

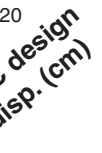

(c)
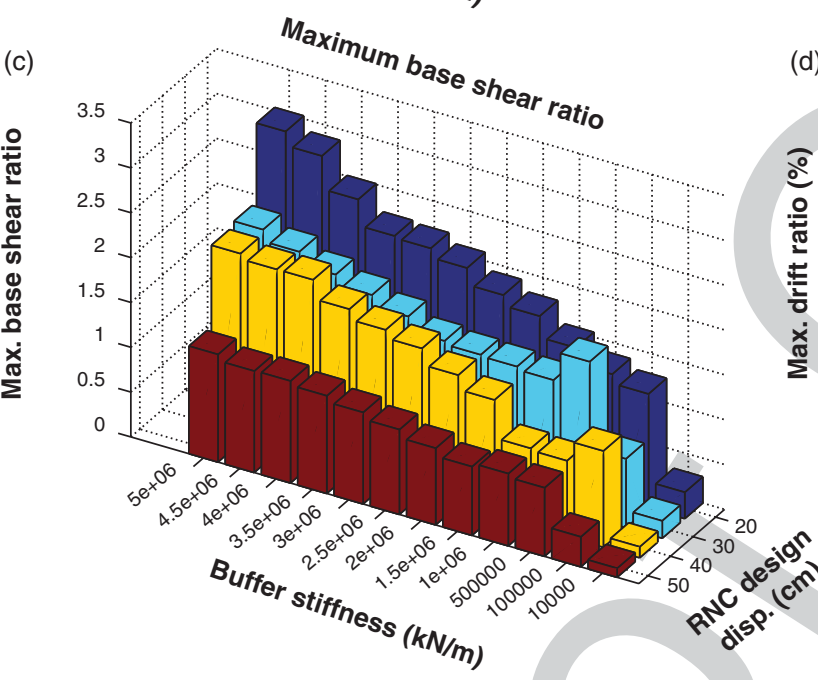

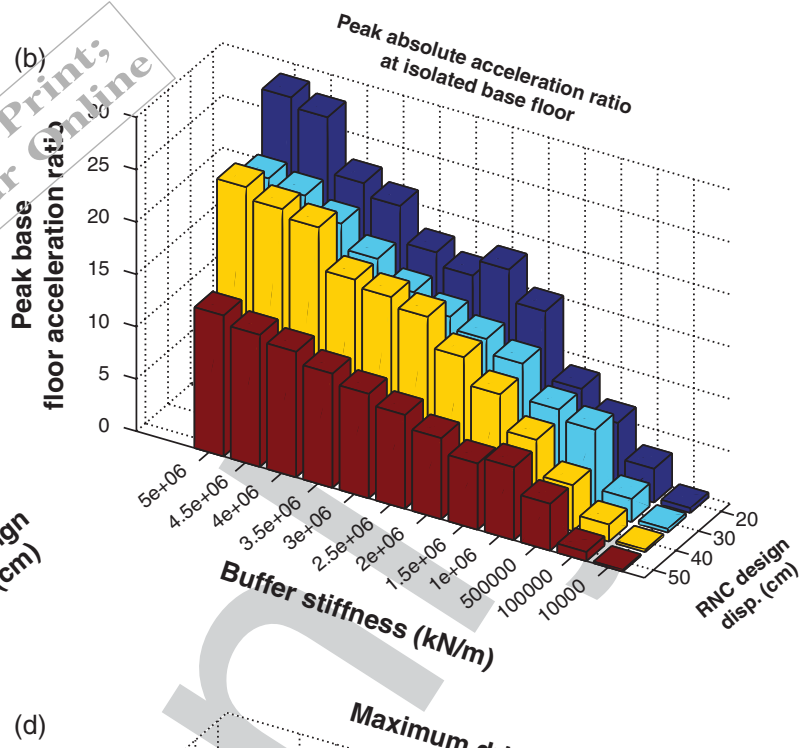

(d) Maximum drift ratio
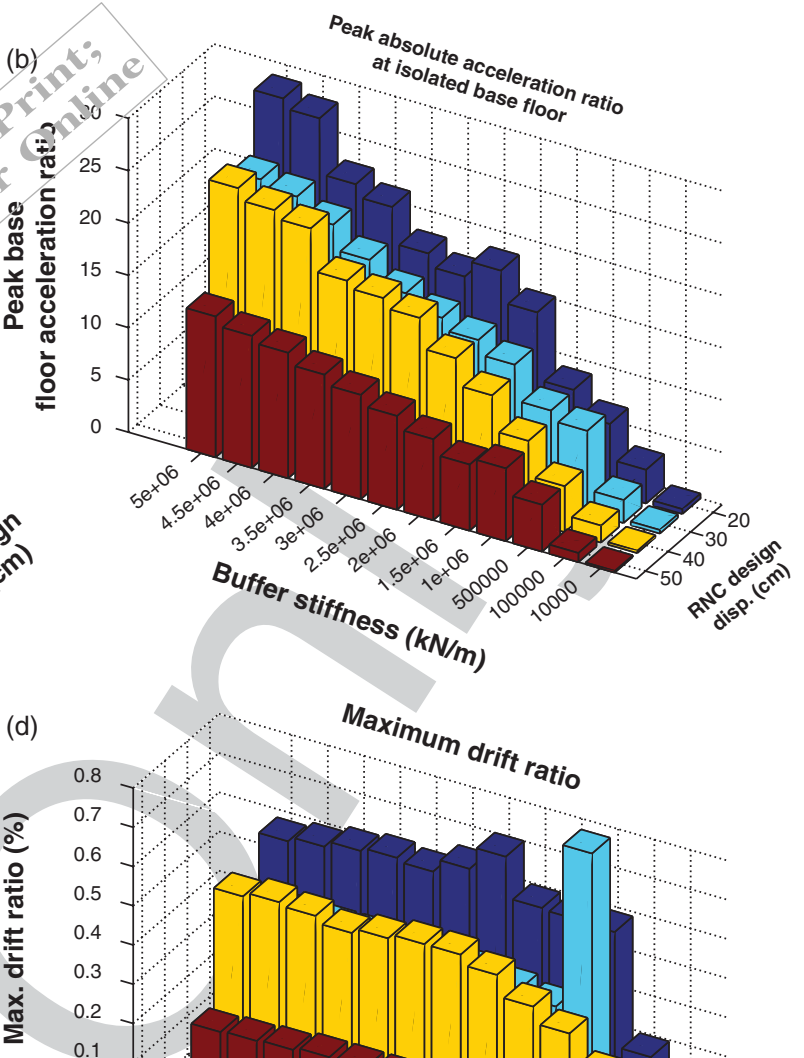

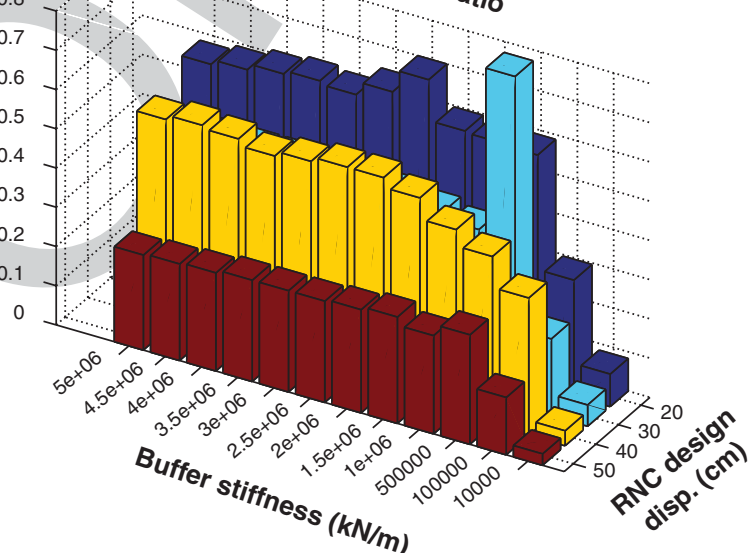

2055

Figure 15. Peak response quantities ratios (isolated/fixed) against seismic gap width and buffer stiffness for different isolator's design displacements under Northridge earthquake: (a) absolute acceleration at the topmost floor; (b) absolute acceleration at the isolated base floor; (c) base shear; (d) drift ratio.

structural acceleration ratios at the topmost floor and the isolated base floor, respectively. Only at very small buffer stiffness, the peak acceleration ratios are acceptable. Such acceleration ratios become worse, more amplified, with the increase in buffer stiffness and the decrease in RNC isolator's design displacement, similar to the variation of maximum base shear ratio in Figure 15(c) and the peak drift ratio of Figure 15(d) against bearing design displacement and its buffer stiffness. The peak drift ratios of Figure 15(d) may be acceptable under severe loading conditions because the majority of their values are less than or equal to $0.50 \%$, which means negligible structural damage according to Structural Engineers Association of California (SEAOC, 1999). Moreover, all drift ratio percentages of Figure 15(d) are significantly lower than $1.5 \%$, which means minor to moderate damage as stated in (SEAOC, 1999).

\subsection{Appropriate RNC isolator characteristics for NF isolation with limited seismic gaps}

This section attempts to mitigate, or even eliminate, the negative influence of the RNC isolator's pounding on structural response. The study target is to minimise or prevent structure-to-structure pounding using the RNC isolator with minimum or no arising drawbacks. One attempt intends to directly deal with the already existing $\mathrm{RNC}$ isolator pounding. This is achieved through the insertion of some extra damping units (EDUs) shown in Figure 16 at the isolation level between the RNC isolator devices, such that the EDUs are arranged symmetrically to generate no torsional responses. The EDUs have the same height as the used RNC isolators and are fixed similarly to the upper isolated base mass and to the lower foundation part. The EDUs combine many non-touching metallic yield dampers to provide additional hysteretic damping 


\section{-}

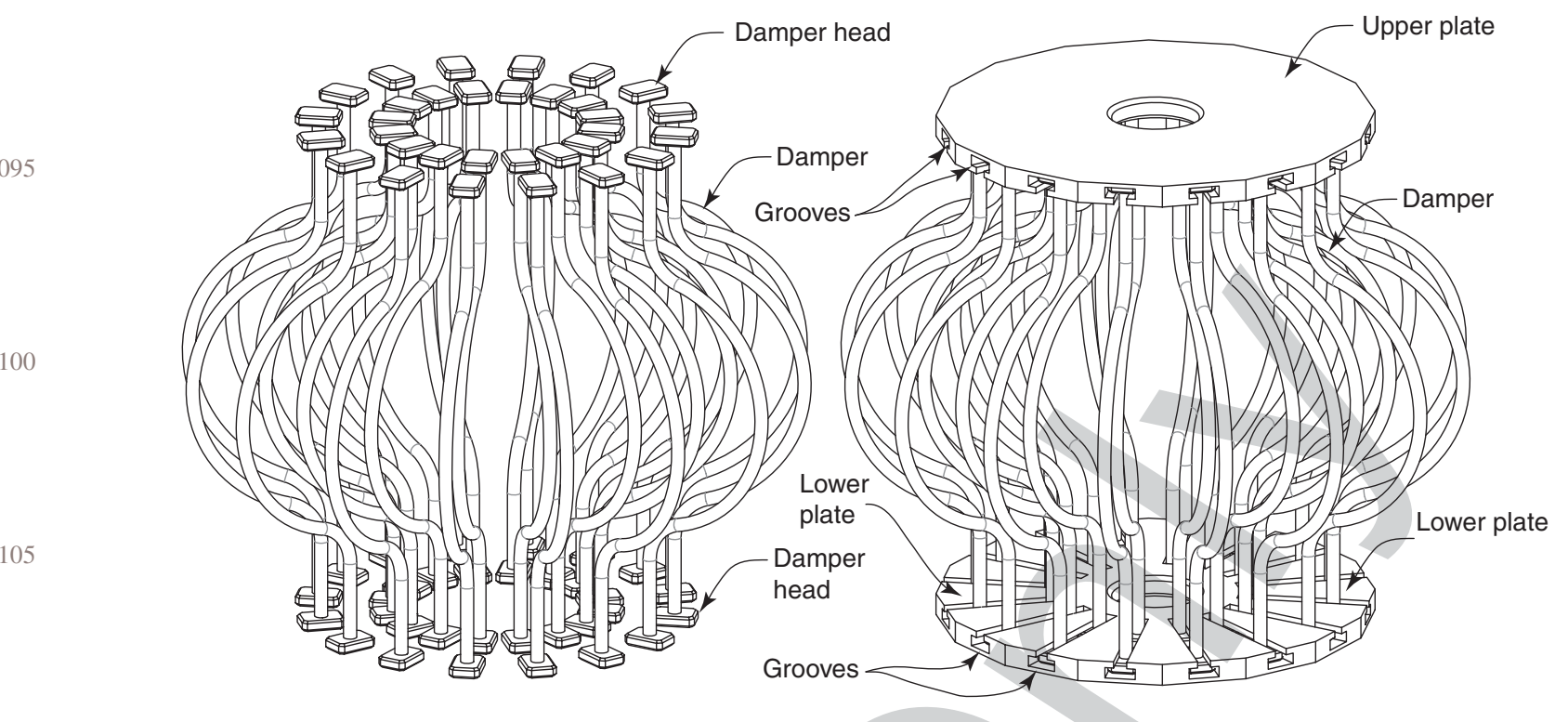

2110 Figure 16. A possible solution for additional metallic yield dampers arrangement.

and/or elastic stiffness. In this study, 15 EDUs are used, each comprises 32 metallic yield dampers made of lead and having a diameter of $60 \mathrm{~mm}$ to mainly provide adequate additional damping with negligible stiffness at the isolation level.

The other attempt to avoid the RNC isolator's pounding is through reducing its horizontal flexibility to a degree that allows for some reasonable structure-ground decoupling and prevents any pounding contact of the RNC-isolated structure with adjacent structures. Accordingly, the resulting peak bearing displacement will be lower than a chosen relatively small design displacement of the RNC isolator, while the peak horizontal displace2125 ment of the RNC-isolated structure will be below the selected seismic gap. This could achieve reasonably efficient isolation with no pounding at all.

In this section, the seismic gap between the RNCisolated structure and the surrounding adjacent one is where $x_{\text {des }}$ is the RNC isolator's design displacement and $S$ is the horizontal separation distance, between two fixedbase structures $\mathrm{A}$ and $\mathrm{B}$, which is obviously equal to the peak relative displacement response $x_{\text {rel }}$ between those adjacent fixed-base structures. The separation distance $S$ is given by Jeng, Kasai, and Maison (1992) and Penzien (1997)

\section{Seismic gap of an RNC - isolated structure}

$$
\leq x_{\mathrm{des}}+\frac{S_{\mathrm{AB}}}{2} \text {, }
$$

$$
S_{\mathrm{AB}}=x_{\mathrm{rel}}=\sqrt{x_{\mathrm{A}}^{2}+x_{\mathrm{B}}^{2}-2 \rho_{\mathrm{AB}} x_{\mathrm{A}} x_{\mathrm{B}}},
$$

where $x_{\mathrm{A}}, x_{\mathrm{B}}$ and $x_{\text {rel }}$ are the mean peak displacement values of the two adjacent structures and their relative displacement, respectively. Based on the period ratio $r=T_{\mathrm{B}} / T_{\mathrm{A}}$, the correlation coefficient $\rho$ is given by Der Kiureghian (1980) and Grigoriu (1981) for two adjacent structures with equal damping ratio $\xi$ as

$$
\rho_{\mathrm{AB}}=\frac{8 \xi^{2}(1+r) r^{3 / 2}}{\left(1-r^{2}\right)^{2}+4 \xi^{2} r(1+r)^{2}}
$$

In this section, the design displacement of the RNC isolator is taken as $30.0 \mathrm{~cm}$, while the calculated separation distance according to Equations (9) and (10) is found to be $25.20 \mathrm{~cm}$. Therefore, and according to Equation (8), a relatively small seismic gap is considered in this section as $38.0 \mathrm{~cm}$.

Figure 17 demonstrates the results of the abovementioned two attempts to achieve efficient seismic isolation under severe NF earthquakes considering limited seismic gaps. Two identical RNC-isolated structures are considered. The first is provided with 15 EDUs and has a fundamental vibration period of $2.0 \mathrm{~s}$ to permit pounding, while the other has no EDUs and has a fundamental vibration period of $1.0 \mathrm{~s}$ to avoid any pounding under the most severe ground excitation among the three NF earthquakes of Table 2, and consequently under the other two relatively weaker ones. According to Figure 17(a)(d), it seems evident that the existence of pounding, regardless of its source, always deteriorates the isolation efficiency because the resulting peak absolute structural acceleration and base shear are times their corresponding values in a fixed-base structure. However, the addition of the EDUs has significantly reduced the peak structural response quantities as well as the pounding intensity of 

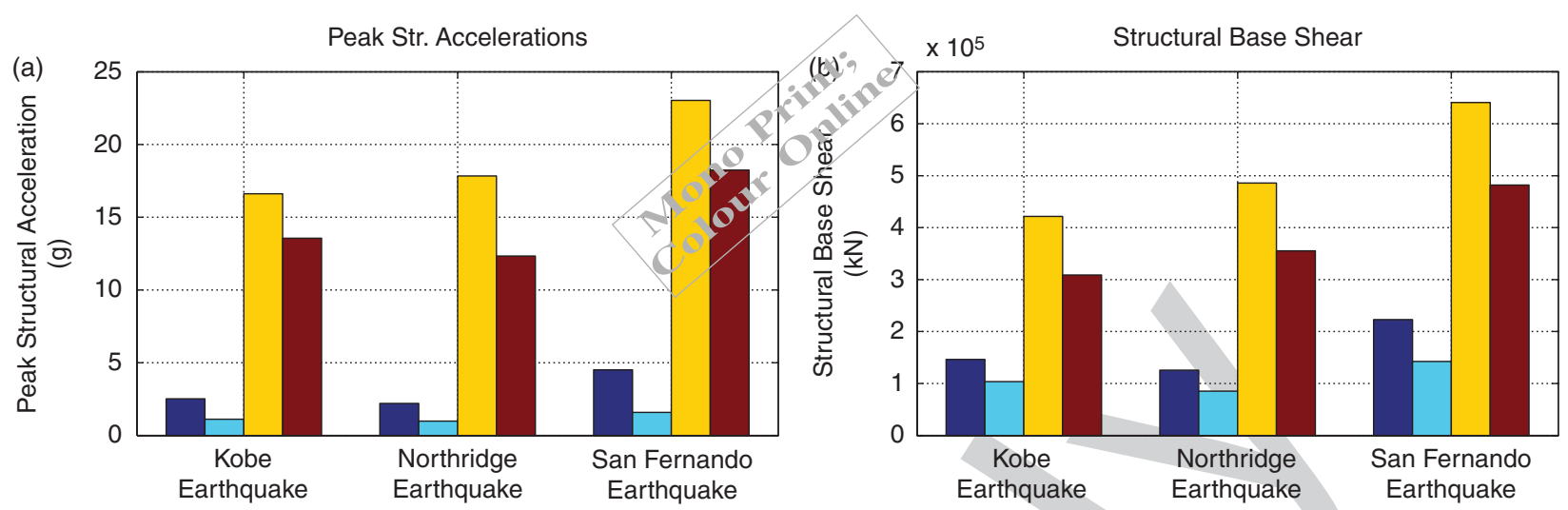

Corresponding Structural Pounding
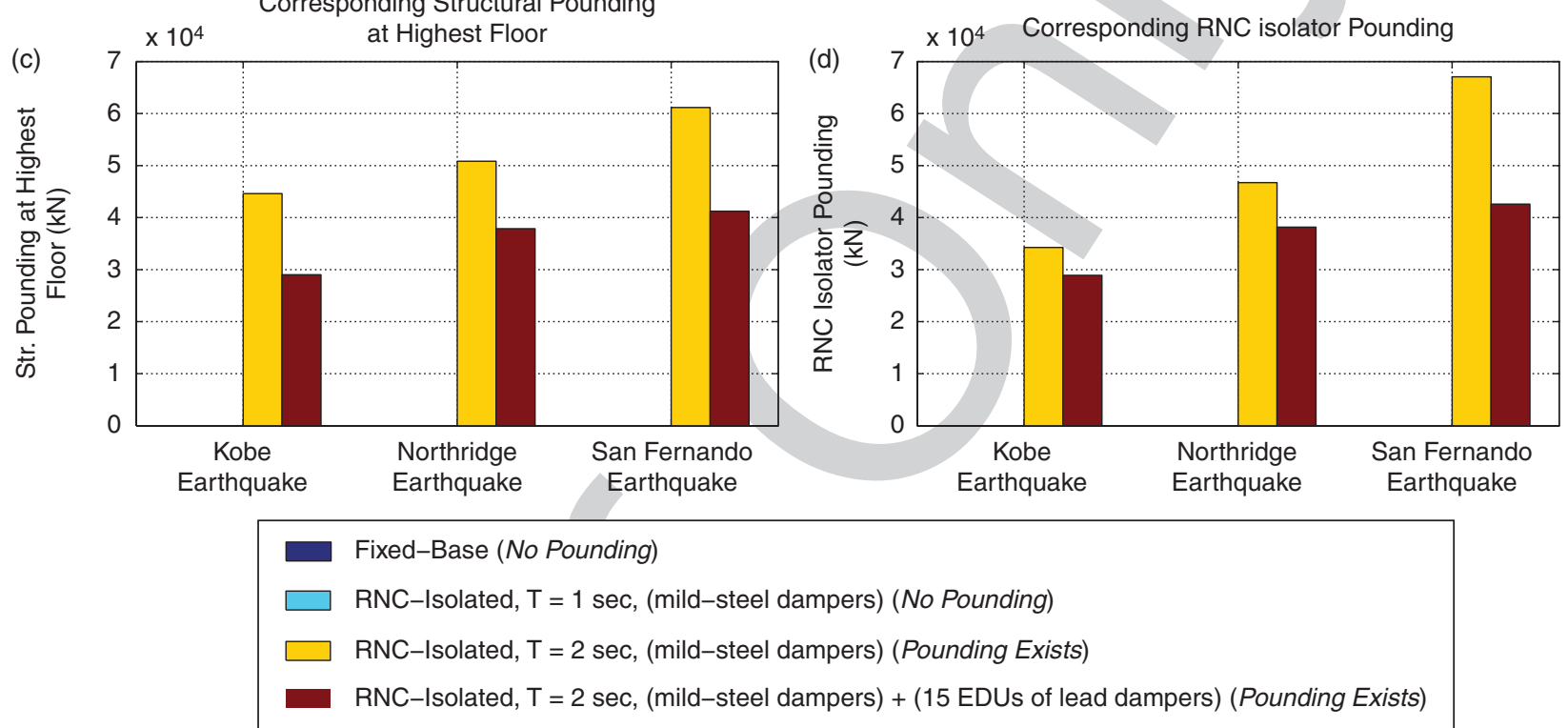

Figure 17. Two attempts to achieve efficient seismic isolation under severe NF earthquakes considering limited seismic gaps: (a) peak structural accelerations; (b) structural base shear; (c) corresponding structural pounding at the highest floor; (d) corresponding RNC isolator pounding.

both structure-to-structure pounding and RNC isolator inner pounding. This observation of the EDUs behaviour may motivate more future studies on their ability to mitigate pounding.

On the other hand, the attempt of using a less-flexible $\mathrm{RNC}$ isolator seems to be more practical in achieving reasonably efficient seismic isolation with no structural nor RNC isolator's inner pounding, especially under the selected most severe NF San Fernando earthquake. To fairly judge the efficiency of this second attempt under the limited seismic gap and RNC isolator's design displacement, a trial and error design process is carried out to reach the most adequate RNC isolator design characteristics under each of the three considered NF ground motions individually. This aims at finding the maximum possible reduction percentage of the RNCisolated structure responses just before exceeding the chosen RNC isolator design displacement or the selected seismic gap to get no pounding anywhere. Figure 18 demonstrates the peak absolute structural acceleration time history and some other main peak response quantities considering the most adequate design of the RNC isolator under each of the three NF ground motions. The main outcome of this figure is that the RNC isolator is able to reduce the peak structural response quantities to a reasonably accepted degree at very small isolation periods under severe NF earthquakes and limited seismic gaps with absolutely no structure-to-structure pounding nor RNC inner pounding.

\section{Conclusions}

This paper evaluated the seismic behaviour of closely spaced fixed-base building structures in NF zones considering structural pounding at different heights, from one or both sides and at different gap width 

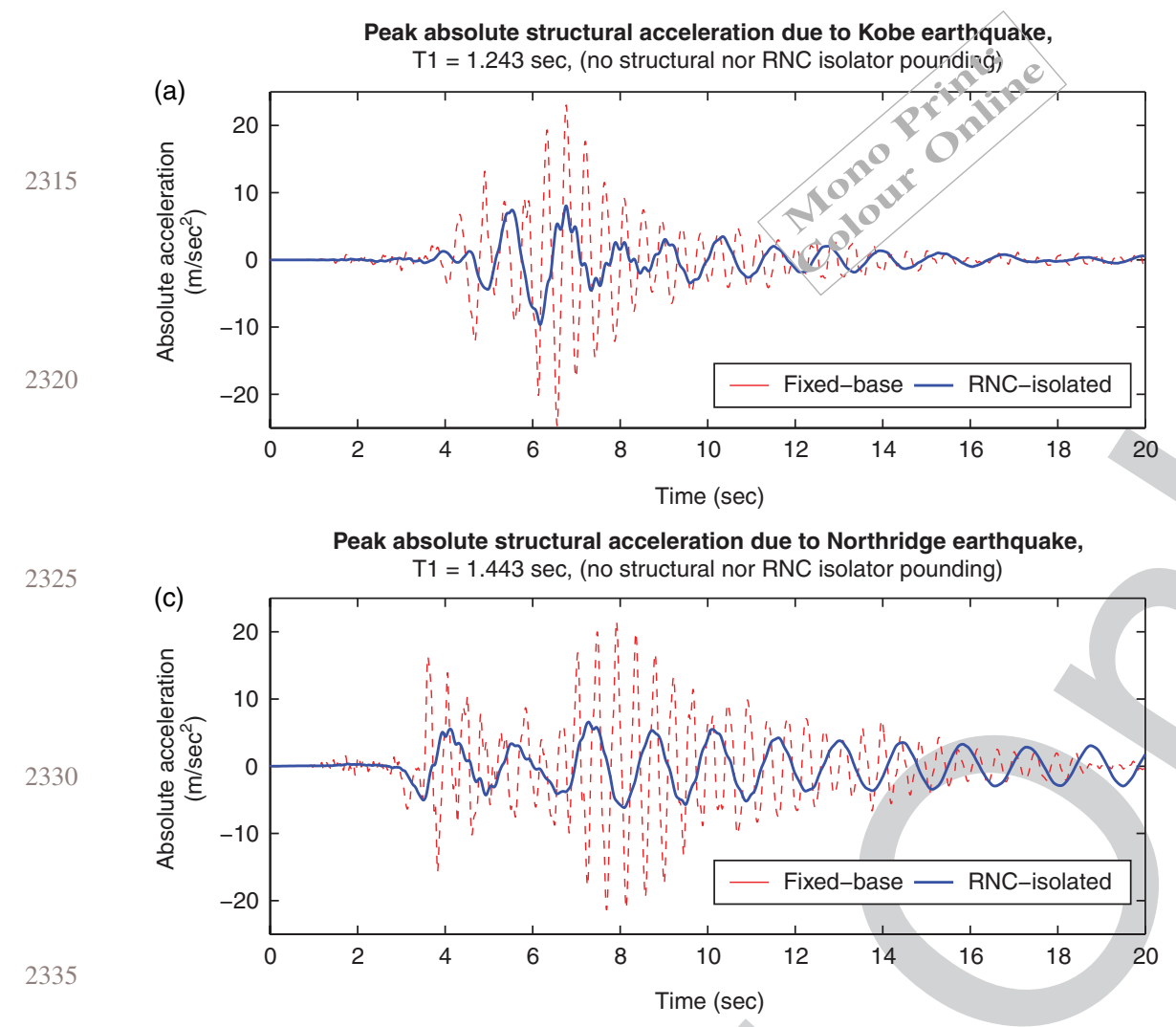

\section{.}

\section{(d)}

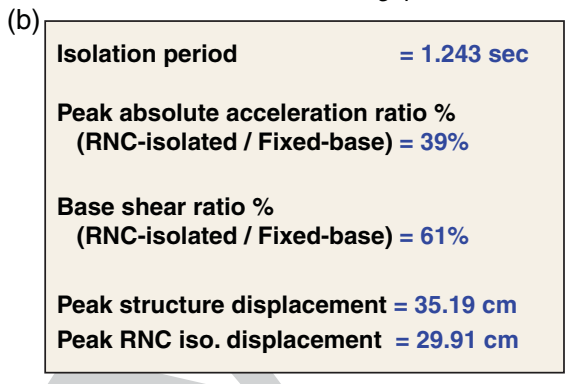

Peak response quantities

RNC Xdes $=30 \mathrm{~cm}$, Seismic gap $=38 \mathrm{~cm}$

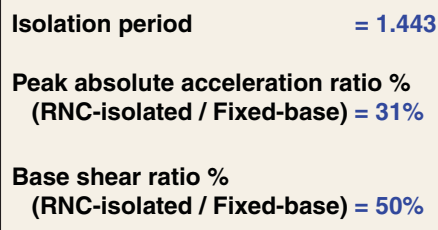

Peak structure displacement $=32.95 \mathrm{~cm}$

Peak RNC iso. displacement $=29.39 \mathrm{~cm}$

Peak absolute structural acceleration due to San Fernando earthquake, $\mathrm{T} 1=1.00 \mathrm{sec}$, (no structural nor RNC isolator pounding)

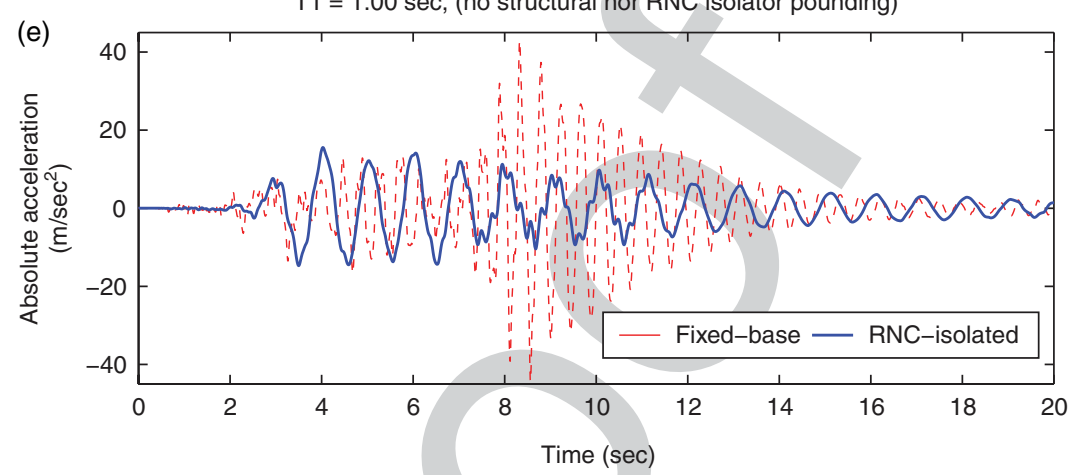

Peak response quantities RNC Xdes $=30 \mathrm{~cm}$, Seismic gap $=38 \mathrm{~cm}$

\begin{tabular}{|c|c|}
\hline Isolation period & $=1.000 \mathrm{sec}$ \\
\hline \multicolumn{2}{|c|}{$\begin{array}{l}\text { Peak absolute acceleration ratio \% } \\
\text { (RNC-isolated / Fixed-base) }=35 \%\end{array}$} \\
\hline \multicolumn{2}{|c|}{$\begin{array}{l}\text { Base shear ratio } \% \\
\quad(\text { RNC-isolated } / \text { Fixed-base) }=64 \%\end{array}$} \\
\hline Peak structure d & $\mathrm{t}=37.56 \mathrm{~cm}$ \\
\hline Peak RNC iso. di & $=29.06 \mathrm{~cm}$ \\
\hline
\end{tabular}

Figure 18. Lowest response quantities of the RNC-isolated structure considering the appropriate RNC isolator characteristics to achieve isolation without any pounding at a seismic gap of $38 \mathrm{~cm}$ and an RNC isolator design displacement of $30 \mathrm{~cm}$ : (a) peak absolute structural acceleration under Kobe earthquake; (b) peak response quantities under Kobe earthquake; (c) peak absolute structural acceleration under Northridge earthquake; (d) peak response quantities under Northridge earthquake; (e) peak absolute structural acceleration under San Fernando earthquake; (f) peak response quantities under San Fernando earthquake.

through nonlinear time-history analysis. Then, the paper presented a recently proposed seismic isolation system, with an inherent buffer mechanism, as a nontraditional solution to avoid direct pounding of isolated structures with their surrounding adjacent buildings. Besides achieving anti-seismic protection, the used approach aims at optimising the possible damage repair and the needed maintenance works after earthquakes. The used isolation system is referred to as the RNC isolator.

The obtained results showed that the peak structural responses due to pounding are usually located within the top third of structure height, particularly the topmost floor as in stiff structures, except the cases of heavy mass and flexible structures where the amplified peak responses are worse and take place at the pounding floor level. It was also found that the RNC isolator's buffer mechanism is able to draw down any possible pounding of the isolated superstructure to be within the isolator solid limits. This entirely prevents direct 
structure-to-structure pounding but on the account of amplifying its acceleration and drift responses. However, such amplified responses might lead to only minor or moderate structural damage under severe NF earthquakes with $1.20 \mathrm{~g}$ PGA. Nevertheless, such damage could be avoided entirely using stiffer RNC isolators to achieve seismic response reductions up to $69.0 \%$ under the same severe loading conditions and limited seismic gaps with no seismic pounding at all.

In this paper, the main two unique advantages of using the RNC isolator with respect to the other available isolation systems are its inherent buffer mechanism, which is able to entirely prevent direct seismic pounding of isolated superstructures, and the device's ability to provide efficient seismic isolation at small isolation periods of $1.0 \mathrm{~s}$ under strong NF earthquake having high displacement and velocity pulses. This low isolation period represents nearly one-half or one-third of the needed isolation periods of other isolation systems to start being effective. Thanks to the adopted rolling motion mechanism of the RNC isolator, which requires less lateral force to initiate isolation compared to elastomeric and friction-based isolation devices.

\section{Disclosure statement}

No potential conflict of interest was reported by the authors.

\section{Funding}

The first author gratefully acknowledge the financial support of Professor José Rodellar, the director of CoDAlab laboratory and research group at the Technical University of Catalonia, Barcelona, Spain, to entirely accomplish the experimental validation of the RNC isolator.

\section{Note}

1. Email: mohammed.ismail@upc.edu

\section{References}

Agarwal, V., Niedzwecki, J., \& va de Lindt, J.W. (2007). Earthquake induced pounding in friction varying base isolated buildings. Engineering Structures, 29, 2825-2832.

American Association of State Highway and Transportation Officials LRFD. (2005). Bridge design specifications, SI units (3rd edn.).: Author.

Anagnostopoulos, S. (1988). Pounding of buildings in series during earthquakes. Earthquake Engineering and Structural Dynamics, 16, 443-456.

Computers and Structures, Inc. (2012). SAP2000, Release 15.1.0 documentation. Berkeley, CA: Author.

2470 Der Kiureghian, A. (1980). Structural response to stationary excitation. ASCE Journal of the Engineering Mechanics Division, 106, 1195-1213.

Grigoriu, M. (1981). Mean-square structural response to stationary ground acceleration. ASCE Journal of the Engineering Mechanics Division, 107, 969-986.
Ismail, M. (2009). An innovative isolation device for aseismic design. ( $\mathrm{PhD}$ thesis. Technical University of Catalonia, Barcelona, Spain). Retrieved November 10, 2009, from http://www.tdx.cat/handle/10803/6265

Ismail, M. (2013). Inner pounding control of a self-stopping seismic isolation system under near-fault motions. Engineering Structures, submitted for publication.

Ismail, M., Casas, J., \& Rodellar, J. (2013). Near-fault isolation of cable-stayed bridges using RNC isolator. Engineering Structures, 56, 327-342.

Ismail, M., Ikhouane, F., \& Rodellar, J. (2009). The hysteresis Bouc-Wen model, a survey. Journal of Archives of Computational Methods in Engineering, 16, 161-188.

Ismail, M., \& Rodellar, J. (2013). A mechanical extension for Stewart platform (Hexapod). Patent No. P201331348. Spanish Office of Patents and Marks.

Ismail, M., \& Rodellar, J. (2014a). Experimental mechanical characterization of a rolling-based seismic isolation system. In The 6th world conference on structural control and monitoring (6WCSCM), July 15-17, Barcelona, Spain, pp. $1148-1157$.

Ismail, M., \& Rodellar, J. (2014b). Experimental mechanical characterization of a rolling-based seismic isolation system. Engineering Structures, submitted for publication.

Ismail, M., \& Rodellar, J. (2014c). A multi-purpose testing platform using HEXAPOD. In The 6th world conference on structural control and monitoring (6WCSCM), July 15-17, Barcelona, Spain, pp. 1045-1056.

Ismail, M., Rodellar, J., \& Ikhouane, F. (2008). Method for the seismic isolation of a supported object. Patents No. WO2010000897A1, ES20080002043, P200802043, PCT/ ES2009/000351. Spanish Office of Patents and Marks.

Ismail, M., Rodellar, J., \& Ikhouane, F. (2009a). An innovative isolation bearing for motion-sensitive equipment. Journal of Sound and Vibration, 326, 503-521.

Ismail, M., Rodellar, J., \& Ikhouane, F. (2009b). Performance of structure-equipment systems with a novel roll-ncage isolation bearing. Computers and Structures, 87, $1631-1646$.

Ismail, M., Rodellar, J., \& Ikhouane, F. (2010). An innovative isolation device for aseismic design. Engineering Structures, $32,1168-1183$.

Ismail, M., Rodellar, J., \& Ikhouane, F. (2012). Seismic protection of low- to moderate-mass buildings using RNC isolator. Structural Control and Health Monitoring, 19, 22-42.

Ismail, M., Rodellar, J., \& Pozo, F. (2014). An isolation device for near-fault ground motions. Structural Control and Health Monitoring, 21, 249-268.

Jangid, R., \& Kelly, J. (2001). Base isolation for near-fault motions. Earthquake Engineering and Structural Dynamics, 30, 691-707.

Jeng, V., Kasai, K., \& Maison, B. (1992). A spectral difference method to estimate building separations to avoid pounding. Earthquake Spectra, 8, 201-223.

Komodromos, P. (2008). Simulation of the earthquake-induced pounding of seismically isolated buildings. Computers and Structures, 86, 618-626.

Makris, N., \& Black, C. (2004). Evaluation of peak ground velocity as a good intensity measure for near-source ground motions. ASCE Journal of Engineering Mechanics, 130, 1032-1044.

Makris, N., \& Chang, S. (2000). Effect of viscous, viscoplastic and friction damping on the response of seismic isolated structures. Earthquake Engineering and Structural Dynamics, 29, 85-107.

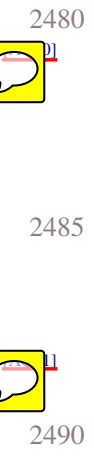


NSIE 993660—26/12/2014—MOHANRAJ.D—501567—-Style 4

Matsagar, V., \& Jangid, R. (2003). Seismic response of baseisolated structures during impact with adjacent structures. Engineering Structures, 25, 1311-1323.

Murat, D., \& Srikanth, B. (2007). Equivalent linear analysis of seismic-isolated bridges subjected to near-fault ground motions with forward rupture directivity effect. Engineering Structures, 29, 21-32.

Pant, D., \& Wijeyewickrema, A. (2012). Structural performance of a base-isolated reinforced concrete building subjected to seismic pounding. Earthquake Engineering and Structural Dynamics, 41, 1709-1716.

Penzien, J. (1997). Evaluation of building separation distance required to prevent pounding during strong earthquakes. Earthquake Engineering and Structural Dynamics, 26, 849-858.

Polycarpou, P., \& Komodromos, P. (2010). Earthquake-induced poundings of a seismically isolated building with adjacent structures. Engineering Structures, 32, 1937-1951.

Structural Engineers Association of California. (1999). Recommended lateral force requirements and commentary. In Seismology Committee. Sacramento, CA: Author.

Uniform Building Code. (1997). International conference of building officials. Author.
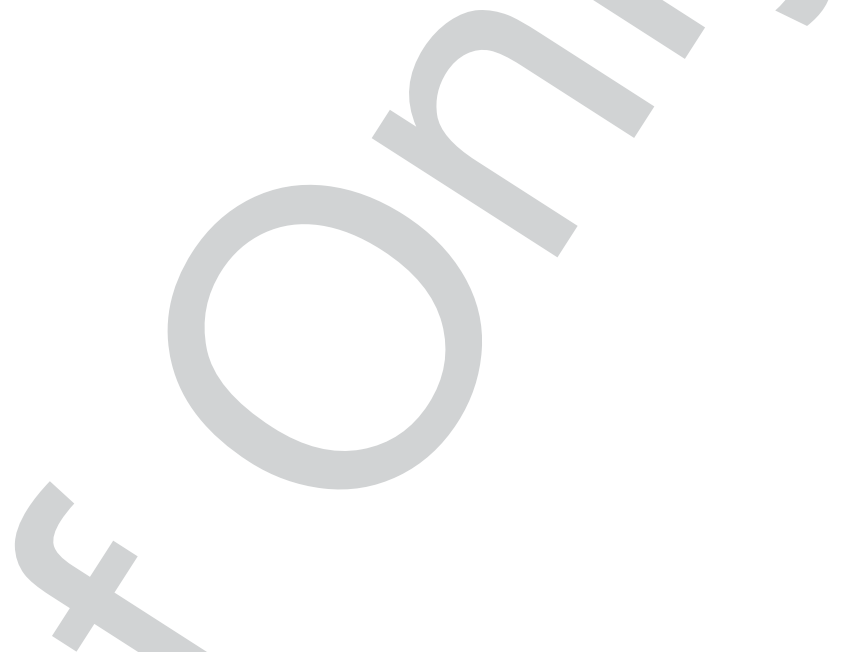